\title{
Dos siglos de elecciones en Centroamérica
}

\section{Two centuries of elections in Central America}

Félix Ulloa hijo 



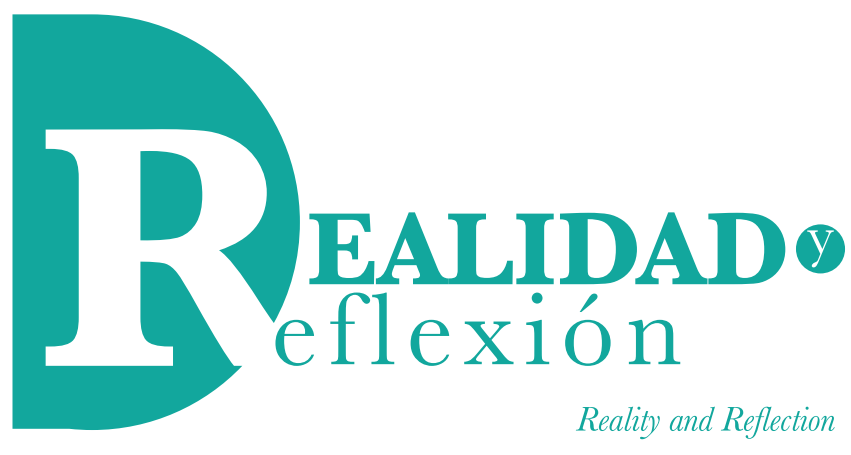

ISSN $1992-6510$

Año 14, No 40, San Salvador, El Salvador, Centroamérica Revista Semestral Julio-Diciembre 2014

Year 14, N40, San Salvador, El Salvador, Central America Semestral Journal July-December 2014

\title{
Dos siglos de elecciones en Centroamérica
}

\author{
Two centuries of elections in Central America
}

Félix Ulloa hijo

Dr. en Derecho

Universidad Complutense de Madrid, España Presidente del Instituto de Estudios Jurídicos de El Salvador (IEJES).

felixulloa0604@gmail.com

\section{RESUMEN.}

El proceso de participación ciudadana en la elección de sus representantes inicia en América Central con la celebración de las Cortes de Cádiz en España. Desde entonces el camino ha sido arduo en todos los países de la región, cada uno con sus particularidades, pero todos con avances y retrocesos muy parecidos.

El repaso histórico del fortalecimiento de la democracia en Centroamérica es el eje central del presente ensayo, que inicia precisamente con la convocatoria para la elección de representantes ante las Cortes de Cádiz en 1810, hasta las reformas electorales generadas mediante la jurisdicción constitucional y ya iniciado el Siglo XXI.

En este trabajo se examinan las experiencias electorales del siglo XIX y las luchas entre liberales y conservadores, para desembocar en un siglo XX donde las reivindicaciones por el sufragio universal y el voto de las mujeres preceden a la lucha armada de los movimientos guerrilleros alzados contra las dictaduras militares, en el contexto de la Guerra Fría y la confrontación USA/URSS. DEMOCRACIA, PARTIDOS POLÍTICOS, ELECCIONES.

\section{ABSTRACT}

The process of citizen participation in the election of their representatives in Central America begins with the celebration of the Courts of Cadiz in Spain. Since then the road has been hard on all countries in the region, each with its own peculiarities, but all very similar advances and setbacks.

The historical review of the strengthening of democracy in Central America is the focus of this essay which begins precisely with the call for the election of representatives to the Courts of Cadiz in 1810, until the electoral reforms generated by the constitutional court and begun the Century XXI.

In this paper the electoral experiences of the nineteenth century are examined and the struggles between liberals and conservatives, to result in the 2oth century where the demands for universal suffrage and the vote for women precede armed guerrilla movements fighting against rebels military dictatorships, in the context of the Cold War and the USA / USSR confrontation. DEMOCRACY, POLITICAL PARTIES, ELECTIONS. 


\section{Introducción}

Centroamérica fue descubierta por Cristóbal Colón en 1502, en su cuarto viaje. Para ese entonces, la población originaria y asentada en estas tierras bordeaba los 6 millones de habitantes. Tres siglos más tarde, después de los años de hierro de la conquista, el sometimiento y la brutal explotación, ${ }^{1}$ ya en los albores de la independencia de la corona española, los centroamericanos no llegábamos al millón de almas. Pérez Brignoli lo relata así:

Para mencionar datos centroamericanos baste decir que de unos 6 millones al momento del contacto, la población indígena descendió a 956 mil en 1550, 546 mil en 1581, 294 mil en 1684, para llegar a unos 587 mil hacia 1800, al final del período colonial. ${ }^{2}$

Cuando hablamos de acercarnos al millón de habitantes, es porque contamos no solo a los españoles y criollos, sino también a los afro descendientes que habían sido traídos como esclavos del continente africano y, los cuales en el decir del obispo de Tlaxcala, José Miguel Guridi y Alcocer, ante las Cortes de Cádiz, formaban parte de la nación española en este lado del Atlántico. En la lucha de Guridi y Alcocer por su reconocimiento como miembros de la nación -y por la supresión del abominable régimen de castas-, éste contó con el apoyo de José Simeón de Uría, obispo de Guadalajara, en la redacción del AArt. 22 de la Constitución promulgada el 19 de marzo de 1812.

Art. 22. A los españoles que por cualquier línea son habidos $y$ reputados por originarios del África, les queda abierta la puerta de la virtud y del merecimiento para ser ciudadanos: en su consecuencia las Cortes concederán carta de ciudadano a los que hicieren servicios calificados a la Patria, o a los que se distingan por su talento, aplicación y conducta, con la condición de que sean hijos de legítimo matrimonio de padres ingenuos; de que estén casados con mujer ingenua, $y$ avecindados en los dominios de las Españas, y de que ejerzan alguna profesión, oficio o industria útil con un capital propio.

Llegamos al siglo XXI con sustanciales cambios sucedidos en el istmo desde 1824, cuando las cinco provincias se reunieron en el Congreso Constituyente para proclamar la República Federal de Centroamérica y que en su Declaración de Independencia Absoluta proclamada en julio de 1823, habían afirmado su independencia de cualquier potencia del viejo o del nuevo mundo. ${ }^{3}$

En la actualidad, Centroamérica es un espacio comunitario que convoca siete países soberanos y, con base en el Protocolo de Tegucigalpa de 1991, ha creado un andamiaje institucional que reúne en el Sistema de Integración Centroamericana (SICA) los órganos fundamentales que reproducen el modelo republicano del Ejecutivo (cumbres presidenciales), Legislativo (Parlamento Centroamericano), Judicial (Corte Centroamericana de Justicia), así como una serie de organismos ejecutivos: Secretaría General, Comité Consultivo, Comité Ejecutivo, etc.

A la fecha somos casi 60 millones de habitantes ${ }^{4}$ en esta región del hemisferio, viviendo en una superficie territorial de 
aproximadamente 570,000 Km2, es decir si incluimos a la República Dominicana que, como Estado asociado, forma parte del SICA. Es decir, que superamos a España y a muchos estados de la comunidad internacional en territorio y población, lo cual nos colocaría frente al dilema de convertirnos en potencia media o seguir el avieso destino de Estados pequeños y débiles que, en el decir de Palou, son aquellos que "independientemente de su situación económica y de desarrollo, poseen un territorio y/o una población reducidos y una participación limitada en los asuntos internacionales". ${ }^{5}$

Pero territorio y población son solo dos de los elementos constitutivos del Estado. La organización institucional del poder es fundamental para su caracterización, por eso echaremos una mirada retrospectiva de doscientos años de alcance, para recordar los primeros ensayos electorales que dieron origen y han venido perfilando la presente identidad política y cultural de los centroamericanos.

Leer en clave electoral este periodo de la historia puede ser el hilo conductor como para comprender otros desarrollos en nuestra compleja realidad.

\section{Cortes de Cádiz y la Constitución de 1812}

En el marco de la llamada Guerra de Independencia de España (1808-1814), generada por la ocupación napoleónica, se convocó a las Cortes de Cádiz, las cuales se reunieron por primera vez el 24 de septiembre de 1810 .

La resolución de la Junta Central sobre la convocatoria por estamentos se libró en
Sevilla el 21 de enero de 1810, en los términos siguientes:

La Junta Suprema gubernativa del Reino, en vista de la consulta de la Comisión de Cortes sobre la forma de convocar a los Prelados y a los grandes a las Cortes generales del Reino, y modo de concurrir y votar en ellas; conformándose con el dictamen extendido en dicha consulta, se ha servido resolver: 1. Que los Prelados en ejercicio y los grandes sean convocados individualmente y según la forma antigua expresada en las copias que la Comisión ha acompañado, y que devuelvo a Vuestra Alteza Serenísima para el uso conveniente; 2. Que uno y otro Estamento, ya esté reunido en el Congreso, ya separado de él, vote por orden y no por cabezas; 3. Que, reuniéndose los dos brazos en una Cámara separada, tengan en ella un solo voto para la deliberación de los negocios, reformándose en esta parte el acuerdo tomado anteriormente en razón de este asunto. De Real orden lo participo a Vuestra Alteza Serenísima para inteligencia y gobierno de la Comisión. Dios guarde a Vuestra Alteza Serenísima muchos años.

Como podemos observar, el voto se ejercería de forma estamentaria y además no se convocaba a los representantes de las colonias americanas.

En vista de la necesidad de enfrentar a Napoleón y que los costos de las operaciones militares se cargaban bastante a las finanzas coloniales, se decidió integrar a las Cortes a representantes de las colonias de ultramar 
en América y Asia. La representación americana se vio condicionada por dos hechos: los levantamientos insurgentes que se generalizaban en el continente y la influencia de la ilustración francesa que había prendido sus ideales en amplios sectores liberales.

Resultado del trabajo de esas Cortes fue la Constitución de Cádiz de marzo 1812, dentro de cuyos logros, además de poner fin al Antiguo Régimen (le ancien régime) estuvieron, entre otros, la definición del concepto de Nación y de soberanía nacional, la abolición del voto estamentario y la representación de la nación por cada individuo electo representante, la elección indirecta para ayuntamientos y diputaciones provinciales y el criterio poblacional para la elección de diputados. Un avance notorio que siguió a la eliminación del voto estamentario fue la adopción del sufragio censitario, mediante el cual se habilitó su "universalidad" a los hombres alfabetos que poseían bienes y eran contribuyentes del Estado.

"La diputación centroamericana en las Cortes fue muy homogénea y en su integración confluyeron diversas profesiones complementarias: dos militares, tres eclesiásticos y tres abogados. La excelente formación de los electos contribuyó a que su presencia en la asamblea fuera relevante para afrontar los diversos problemas que el nuevo orden constitucional contemplaba". ${ }^{6} \mathrm{EI}$ costarricense Florencio del Castillo presidió dichas Cortes y el nicaragüense López de la Plata fungió como vicepresidente. Los periodos de ambos se sucedieron en 1813.

Sin duda, las Cortes de Cádiz y la Constitución que promulgaron constituyeron un hito de dimensiones históricas y que, para nuestra nación centroamericana, marcaría un rumbo a seguir en los años venideros. La vigencia de esa carta magna fue muy corta (dos años) dada su derogatoria cuando Fernando VII regresó a España en 1814; sin embargo, se vio forzado a restablecerla durante el Trienio Liberal (1820-1823).

Entre los efectos del Trienio se declaró en Centroamérica la libertad de imprenta. El doctor e independentista guatemalteco Pedro Molina Mazariegos aprovechó esta oportunidad y fundó "El Editor Constitucional", a través del cual promovió la independencia. A su vez, José Cecilio del Valle fundó "El Amigo de la Patria". Las opciones de Molina y de del Valle dieron lugar al nacimiento de dos partidos políticos: Los Gazistas, de del Valle, y los Cacos, de Molina Mazariegos. Ambos se fueron a elecciones para diputados a cortes, imponiéndose el Partido de del Valle. Pero los Cacos lograron una victoria importante el 9 de marzo de 1821 al colocar al subinspector del ejército Gabino Gaínza como Jefe Político Superior y Capitán General de la Provincia de Guatemala. La independencia de Centroamérica entraba en su recta final.

\section{Independencia y elecciones federales}

Un año antes, en enero de 1820, en una localidad sevillana, el teniente coronel Rafael de Riego, mediante su pronunciamiento llamando a la restauración de la Constitución de Cádiz, daba inicio a un periodo conocido como el Trienio Liberal, con lo que los patriotas independentistas centroamericanos, perseguidos durante el periodo del absolutismo, tuvieron condiciones favorables para continuar la gesta iniciada el 5 de noviembre de 1811 en San Salvador, interrumpida por las capturas 
y posteriores Procesos de Infidencia de 1814. Ya el 24 de febrero de 1821 Agustín de Iturbide había lanzado el Plan de Iguala o Plan de Independencia de la América Septentrional, por ello no extrañó que los eventos promovidos por los Cacos, incluyendo la agitación realizada el viernes por la noche por doña Dolores Bedoya de Molina, esposa de Molina Mazariegos, culminaran el sábado 15 de septiembre de 1821 con la suscripción del Acta de Independencia firmada en el Palacio Nacional de Guatemala.

El camino no fue fácil. A pesar de la docilidad de Gaínza, hubo que luchar contra el anexionismo de Iturbide y contra las propias debilidades imperantes en las cinco provincias que quedaron, puesto que Chiapas, que formaba parte de la Capitanía General de Guatemala, decidió integrarse a México. Al parecer la lapidaria expresión del sabio del Valle: "Ayer ordeñaban vacas... hoy quieren dirigir naciones" auguraba la fatalidad de su propio destino.

Después de ingentes esfuerzos, la Asamblea Nacional Constituyente de las Provincias Unidas de Centroamérica aprobó el 22 de noviembre de 1824 la Constitución de la República Federal de Centroamérica, con el propósito de forjar una gran república bajo el esquema de la división de poderes y la elección de sus gobernantes y representantes mediante el sufragio popular, regulando en la Sección 5 de su Título III el régimen del sufragio y la forma de elegir a las supremas autoridades. Así, estableció que los representantes serían elegidos uno por cada 30 mil habitantes, los senadores se elegirían popularmente dos por cada Estado y el presidente sería elegido por los pueblos de todos los Estados.

El primer ejercicio electoral federal se realizó en 1825 para elegir al presidente y al vicepresidente de la Federación. De un total de 82 votos asignados, solo se emitieron 79. Los candidatos eran el conservador José Cecilio del Valle, de Honduras, y el liberal Manuel José Arce, de El Salvador. Arce obtuvo 34 votos y del Valle 41 votos. El Congreso, dominado por los liberales, determinó que ninguno obtuvo la mayoría, pues contó los votos sobre la base de 82 y no de 79. Luego, en una votación en su seno, eligió a Arce por 22 votos contra cuatro para del Valle. Desde luego que del Valle desconoció tal elección y rechazó el cargo de vicepresidente.

Como era de esperarse, un nuevo periodo de convulsión política estremeció a la recién creada Federación y la guerra civil desoló los campos del istmo. El presidente Arce salió al campo de batalla y depositó su mandato en el vicepresidente Mariano de Beltranena y Llano, quien había sido nombrado cuando del Valle se negó a aceptar el cargo.

El 13 de abril de 1829, un ejército encabezado por Francisco Morazán entró en la ciudad de Guatemala y derrocó al vicepresidente Beltranena, quien desde febrero de 1828 ejercía interinamente la primera magistratura en sustitución del presidente Arce, quien para entonces ya se había pasado al bando conservador. Morazán dispuso llamar a sesiones al Congreso y al Senado de 1826, cuyo mandato estaba más que extinguido. Esos dos cuerpos eligieron el 25 de julio como presidente provisional a José Francisco Barrundia y Cepeda, quien procedió a convocar elecciones presidenciales y legislativas en 1830. En estas elecciones hubo varios candidatos, pero los más votados fueron Francisco Morazán, con 202 votos, y José Cecilio del Valle, con 103. 
A la hora de reconocer si hubo o no triunfo por elección popular, los congresistas se encontraron con problemas similares a los de 1825: si para establecer mayoría absoluta tomaban en cuenta los votos válidos llegados al Congreso, Morazán triunfaba constitucionalmente y la elección era popular; pero si determinaban la mayoría por el número de votos que debían haber votado, no había elección popular, y entonces el Congreso debía elegir. En 1825 el Congreso resolvió este asunto de acuerdo con la segunda tesis; pero en 1830 se inclinó por la primera y proclamó el triunfo de Morazán.

Dado que el periodo presidencial era de cuatro años, hubo que convocar a elecciones el 2 de junio de 1834. De nuevo compiten los hondureños Morazán y del Valle. Esta tercera vez, del Valle gana las elecciones y se le reconoce la victoria, pero su destino de no gobernar la República Federal estaba escrito y el 2 de marzo, mientras se dirigía a tomar posesión del cargo, muere en la ruta desde Honduras hacia Guatemala, sin Ilegar a recibir la investidura. Ante tal situación, se convoca a elecciones nuevamente para el 2 de febrero de 1835 por parte del Congreso Federal, las cuales fueron ganadas por Francisco Morazán. El 14 de febrero de 1835 fue juramentado como presidente para un segundo mandato que terminaría el 1 de febrero de 1839.

La República Federal tuvo una corta existencia, y después de varias guerras civiles se disolvió en 1839, y los cinco estados de la federación se erigieron en cinco repúblicas independientes. El primer país en separarse definitivamente fue Nicaragua, en abril de 1838. En octubre el Estado de Honduras también abandonó la Federación, y en noviembre se separó Costa Rica, creándose de esta manera los Estados Nacionales. La Federación quedó disuelta con Guatemala, gobernada desde 1840 por Rafael Carrera y la Constitución abrogada de hecho, aunque El Salvador no lo aceptó hasta 1841, cuando decide darse su propia Constitución y crear su propio Estado.

Hubo varios intentos posteriores por reconstruir la Patria Grande, pero no prosperaron. Con la hegemonía conservadora de Rafael Carrera, la Iglesia Católica recuperó muchos de los privilegios materiales que los liberales le habían conculcado, sobre todo en las vastas propiedades y latifundios, garantizados por los contratos enfitéuticos. En materia de control poblacional, fue hasta el nuevo auge de los liberales que en Guatemala llevaron a cabo la conocida Revolución Liberal de 1871, mediante la cual se introdujeron reformas sustanciales ${ }^{7}$ como la separación de la Iglesia y el Estado que, junto con la adopción del Código Civil, creó los registros civiles fuera de los archivos parroquiales, la educación pública gratuita, una banca de fomento, etc. Todas estas reformas constituyeron un avance en la modernización del Estado y prepararon al istmo para su inserción en el siglo XX.

\section{Primera mitad del siglo XX}

En varios países de la región las formaciones decimonónicas adscritas a los conservadores y liberales dominaron el escenario político en la primera mitad del siglo. En Honduras y Nicaragua esa forma de bipartidismo fue

\footnotetext{
7 En los primeros años de la Federación, los liberales habían logrado grandes avances con la adopción de instituciones del Código de Livingston, como el jurado popular, o el divorcio que introdujo el jefe de Estado de Guatemala, Mariano Gálvez, en 1831. Luego, en 1873 con Justo Rufino Barrios, quien además de grandes reformas económicas luchó por la reunificación de la República Federal de Centroamérica.
} 
la dominante, mientras El Salvador y Costa Rica abrían espacio a las nuevas ideas que influenciadas por los movimientos obreros llegaban desde Europa. Guatemala heredaría el disfuncionalismo que presenta su actual sistema de partidos desde esa época, cuando la ocupación de la United Fruit Co. (UFC) y sus intereses dominaba el escenario político.

Pero no solo Centroamérica adolecía de esas instituciones sólidas e indispensables de la democracia, pues según Duverger eran entidades que hasta 1850 solo estaban estructuradas en los Estados Unidos de América. Fue Kelsen quien en la primera mitad del siglo XX abrió la posibilidad de que partidos políticos no solo se legitimaran en la democracia, sino que también adquirieran rango constitucional, ${ }^{8}$ tendencia que se confirmaría después de la Segunda Guerra Mundial, en la tradición de la Constitución de la República de Weimar y en la doctrina que Triepel Ilamó "Constitucionalismo racionalizado". El proceso de constitucionalización de los partidos políticos en nuestra América se inicia:

... con la Constitución uruguaya de 1934, que en sus artículos 85 al 88 que se referían a la composición de Senado, otorgó 15 bancas a la lista más votada del partido más votado y quince a la lista que seguía en número de votos, por lo que se le llamó la ley del medio y medio...". Sin embargo, su inmersión en el orden jurídico ya se había producido con antelación. "En México, por ejemplo, la ley electoral de 19 de diciembre de 1911, trató específicamente a los partidos políticos, y señalaba requisitos para intervenir en los procesos electorales; una nueva ley de 20 de setiembre de 1916, incluía todo un capítulo referido a los partidos, tendencia que se recogió en la nueva ley de 6 de febrero de $1917 . .{ }^{9}$

Los partidos políticos se batían entre continuar con las agónicas agendas del s. XIX o adoptar las ideas y planteamientos socialistas que comenzaban a irrumpir en el debate político, entre ellos la adopción del sufragio universal y el fin del voto censitario.

Otro elemento que se introdujo como reivindicación inmediata fue el derecho del voto a las mujeres. Los movimientos feministas en la región tuvieron momentos épicos que marcaron el rumbo irreversible de su lucha. Destacan la creación de la Liga Feminista en Costa Rica en 1923, liderada por la legendaria Sara Casal, o la marcha de las mujeres en San Salvador, reprimida violentamente en 1922, que incentivó los ánimos sufragistas llevando a Prudencia Ayala a proclamarse candidata presidencial en 1931. También el caso de Josefa Toledo de Aguerri, quien además fue la fundadora de las primeras organizaciones feministas, de la Revista Femenina Ilustrada "Mujer Nicaragüense".

Finalmente, y con la legislación salvadoreña que otorga el derecho del sufragio a las mujeres de manera condicional en 1939, y Guatemala que lo reconoce plenamente en 1945, el voto de las mujeres entra en vigor en la segunda mitad del siglo. Costa Rica lo consigna en su Constitución de 1949, mientras que Honduras y Nicaragua lo reconocen en 1955 . 


\section{Segunda mitad del siglo $X X$}

Después de la Segunda Guerra Mundial, sacudido el yugo de la UFC y con los cambios de la Revolución de 1944, Guatemala, al igual que el resto de Centroamérica, entra en la ola renovadora que inspira la Declaración Universal de los Derechos Humanos de diciembre de 1948, cuyo AArt. 21 consagra el sufragio activo y pasivo como derecho humano y lo acompaña de un mecanismo mediante el cual se deberán desarrollar elecciones libres, periódicas y mediante el sufragio universal.

Sin embargo, la región se vería afectada por factores y hechos externos que modificarían el decurso de su historia. En primer lugar, el inicio de la guerra de Corea en 1947 marca el inicio de la llamada Guerra Fría, que no fue otra cosa que la confrontación de las dos superpotencias USA/URSS y la salvaguarda de sus zonas de influencia, etapa también conocida como confrontación Este/Oeste.

Nosotros quedamos en la órbita de los Estados Unidos de América. El otro evento fue el triunfo de la Revolución Cubana en 1959 y su alineamiento al bloque soviético. Estos dos hechos marcarían no solo el destino de nuestros pueblos, sino que también condicionarían el funcionamiento de los sistemas políticos y electorales a la salvaguarda de los intereses de los Estados Unidos de América en la región, de por sí geopolíticamente estratégica.

A causa de la confrontación ideológica que vivió el mundo en ese periodo, el destino de los partidos políticos fue sombrío, a pesar del "constitucionalismo racionalizado y democrático" en la Europa Occidental. En los países del llamado bloque soviético, la imposición del partido único aplastó cualquier esfuerzo de pluralismo; primero, amparados en el dogma de la dictadura del proletariado y, posteriormente, bajo el marco doctrinario de "la soberanía limitada" anunciada por Leonid Brezhnev.

En tanto, de este lado del Atlántico, los Estados Unidos de América sostenían modelos autoritarios y dictaduras militares maquilladas de democracias formales mediante periódicas mascaradas electorales, en las cuales el pluralismo y la competitividad eran válidos únicamente para los partidos políticos de los diferentes signos conservadores. Las fuerzas progresistas, democráticas o revolucionarias de izquierda, fueron proscritas y perseguidas, su exclusión llegó a institucionalizarse en los sistemas normativos, y los esfuerzos organizativos de sus personeros tuvieron como precio la cárcel, el exilio, la muerte y cuando menos, el ostracismo social.

La doctrina de la seguridad nacional y la teoría del enemigo interno, habilitaron regímenes dictatoriales y antidemocráticos, cuya única credencial de legitimidad exigida por Washington era su devoción anticomunista. En la defensa del "orden democrático occidental y cristiano" se creó el Tratado Interamericano de Asistencia Recíproca (TIAR) y se expulsó a Cuba de la Organización de Estados Americanos (OEA).

Privilegiar las relaciones con los militares golpistas y autócratas, así como con sectores del gran capital, por parte de los Estados Unidos de América, desechando el diálogo y el entendimiento con sectores democráticos de las clases medias, profesionales y medianos empresarios, generó un clima de confrontación en el interior de nuestros países, que promovió 
la exclusión política, social y económica de amplios sectores mediante regímenes surgidos de cuestionados procesos electorales. Los escandalosos fraudes en las elecciones, los exilios forzados de políticos opuestos a las dictaduras; la persecución contra líderes políticos, gremiales, religiosos, etc. fueron orillando a estos sectores a optar por la lucha armada como vía legítima para disputar el ejercicio del poder público.

\section{Lucha armada y giro democrático}

El triunfo de un puñado de alzados en armas en la Sierra Maestra contra el ejército y el aparato de Gobierno de la dictadura de Fulgencio Batista fue un inequívoco ejemplo a seguir por múltiples movimientos revolucionarios en el continente.

Centroamérica no fue la excepción. A inicios de la década de los 60 varios grupos guerrilleros iniciaron la lucha armada: las Fuerzas Armadas Revolucionarias (FAR) en Guatemala, dirigidas por Marcos Yon Sosa, Luis Turcios Lima y Cesar Montes; el Frente Unido de Acción Revolucionaria (FUAR) en El Salvador, organizado por el Partido Comunista, de muy corta duración porque el PCS hizo un giro hacia una estrategia electoral y abandonó la lucha armada; el Frente Sandinista de Liberación Nacional (FSLN), con Carlos Fonseca a la cabeza, sería el único movimiento que triunfó militarmente el 19 de julio de 1979, derrocando al dictador Anastacio Somoza Debayle.

Demostrada la inviabilidad del método guerrillero en América del Sur, desde la desmovilización de la guerrilla venezolana, la caída de Mariguella en Brasil, Luis de la Puente Uceda en Perú, Massetti en
Argentina y el Che en Bolivia, así como la desarticulación de la guerrilla urbana de los Tupamaros en Uruguay, el ERP de Santucho y los Montoneros de Firmenich, durante las décadas de 1960 y 1970, nadie habría apostado al triunfo sandinista en Nicaragua, menos aún a un poderoso movimiento revolucionario en El Salvador que articulaba las cinco organizaciones político-militares clandestinas que operaban en la ciudad y mantenían zonas rurales bajo su control, llamadas frentes de guerra, y movilizaban amplias organizaciones de masas conformadas por obreros, campesinos, estudiantes, sectores medios y religiosos. Por su parte, Guatemala libraba su propia lucha de liberación, siguiendo los pasos de Nicaragua y El Salvador, sin que las acciones militares llevaran la confrontación a un nivel de guerra civil, como fue el caso de sus vecinos.

En El Salvador la guerra se desencadenó a nivel nacional cuando las cinco organizaciones guerrilleras $^{10}$ se unificaron en octubre de 1980 bajo el nombre de Frente Farabundo Martí para la Liberación Nacional (FMLN) y lanzaron la ofensiva final el 10 de enero de 1981, y no finalizó hasta la firma de los Acuerdos de Paz suscritos en Chapultepec, México, el 16 de enero de 1992.

Ante el alto costo en vidas humanas, infraestructura y demás recursos que demandaba la guerra, su prolongación indefinida por el involucramiento directo del Gobierno de los Estados Unidos de América apoyando a los contrarrevolucionarios nicaragüenses y al Gobierno salvadoreño; y de manera indirecta la URSS vía Cuba y Nicaragua a los revolucionarios de El Salvador

10 Fuerzas Populares de Liberación FPL, Ejército Revolucionario del Pueblo ERP, Resistencia Nacional RN, Partido Comunista Salvadoreño PCS y Partido Revolucionario de los Trabajadores Centroamericano PRTC. 
y Guatemala, tanto los actores nacionales como importantes sectores de la comunidad internacional llegaron a la convicción de que no habría victoria militar que definiera los conflictos en la región y lo mejor era buscar soluciones políticas y negociadas. ${ }^{11}$

En la búsqueda de esas soluciones, los países de la región trataron de fortalecer sus marcos institucionales y les concedieron a los partidos políticos un rango principal.

En las Constituciones y leyes electorales se les consideró como instituciones privilegiadas del sistema democrático. En Costa Rica se le conceptúa en el Art.98 de la Constitución Política y el Código Electoral en el Título III, Art. 48 y ss. En El Salvador, el Art. 85 de la Constitución los define como el único instrumento del pueblo para hacerse representar en el Gobierno.

El Código Electoral los regula en el Título VII, Art. 150 y ss. En Guatemala se les regula constitucionalmente en el Título V, Art. 233 y la Ley Electoral y de Partidos Políticos, en el Libro II, relativo a las "Organizaciones Políticas", las regula a partir del Art. 16 y ss.

En Honduras el Art. 47 de la Constitución los considera instituciones de derecho público y la Ley Electoral y de las Organizaciones Políticas los regula a partir del Título II, Art. 12 y ss. En Nicaragua, el Poder Electoral es el Cuarto Poder de la República, según lo

11 Se calculan unas 250 mil en Guatemala durante los 30 años de lucha armada, más de 150 mil en los años 80 en Nicaragua, 80 mil en El Salvador, sin contar a los desaparecidos, refugiados, discapacitados, viudas y huérfanos. La ayuda militar de la administración republicana de USA a El Salvador era de 3.5 millones de dólares diarios, solo superada por la que recibía Israel. La revolución en Nicaragua creó conflictos de gran magnitud, algunos llevados a la Corte Internacional de Justicia, otros en USA, donde el Congreso, dominado por los demócratas, culminaron con acusaciones a Oliver North por el escándalo Irán/Contras, que salpicaron al presidente Reagan y obligaron a renunciar a altos funcionarios como McFarlaine y Poindexter. establece el Art. 168 de la Constitución y en el Art. 55 de la Constitución se habilita la formación de los partidos políticos.

En cuanto a la Ley Electoral, esta los contiene en el Título V, Art. 50 y ss., considerándolos expresamente como personas jurídicas de derecho público, al igual que Honduras.

En Panamá se les considera organismos funcionales de la Nación. La Constitución los reconoce mediante el Art. 132. El Código Electoral desarrolla su funcionamiento en el Título III, Art. 36 y ss.

\section{Restauración democrática y primera generación de reformas}

La década de 1980 se consideró como la década perdida, dada la conflictividad que vivía la región y las pérdidas que toda guerra genera para las naciones. Sin embargo, en el nivel político fue un periodo cuasi fundacional que generó procesos que culminaron con la elaboración de nuevas constituciones. Honduras aprobó la suya en 1982, El Salvador, en 1983; Guatemala, en 1985 y Nicaragua, en 1987.

A la vez, procesos de diálogo se iniciaron de manera seria y sistemática, los cuales, dadas las particulares condiciones de cada país, tuvieron sus propias dinámicas.

Es importante destacar el papel de la comunidad internacional en estos procesos. Primero, con iniciativas bilaterales como la Declaración Franco-Mexicana de 1981; luego, con esfuerzos de países vecinos como México, Venezuela, Colombia y Panamá, que generaron el Grupo Contadora, hasta el involucramiento directo de Naciones Unidas, y finalmente, los Estados Unidos de 
América, una vez terminada la Guerra Fría con la caída del Muro de Berlín en 1989.

En Nicaragua, donde se intentó desde 1981 un acuerdo patrocinado por Thomas Enders, hasta los Acuerdos de Sapoá en marzo de 1988 firmados por el Gobierno de Nicaragua y la Resistencia Nicaragüense, después de aprobada la nueva Constitución que permitía la firma y el cumplimiento de los compromisos adoptados en la negociación, hubo que pasar por muchas jornadas e iniciativas, casi todas vetadas por la intransigencia del Gobierno republicano de Ronald Reagan.

Igual calvario se vivió en el proceso salvadoreño iniciado con el encuentro en la localidad de La Palma en 1984 entre la delegación del Gobierno y los insurgentes del FMLN. El Acuerdo de Chapultepec firmado en México en 1992 puso fin al conflicto. Previamente $-y$ al igual que en Nicaragua- se habían desarrollado cambios constitucionales (abril 1991), producto de la mesa de negociación, entre ellos la reforma al sistema electoral generando una nueva legislación en la materia y creando una nueva autoridad que administrara los procesos eleccionarios de manera justa e imparcial.

Guatemala llegaría más tarde con el Acuerdo marco sobre democratización para la búsqueda de la paz por medios políticos, conocido como Acuerdo de Querétaro, por haberse firmado en esa ciudad mexicana el 25 de Julio de 1991, entre el Gobierno de Guatemala y la Unidad Revolucionaria Nacional Guatemalteca (URNG), hasta la firma del Acuerdo de Paz firme y duradera, suscrito en ciudad de Guatemala el 29 de diciembre de 1996.
Todos estos procesos tuvieron como punto de partida la suscripción de los Acuerdos de Esquipulas II, el 7 de agosto de 1987, por los presidentes de Guatemala, El Salvador, Honduras, Nicaragua y Costa Rica, para definir el procedimiento que permitiría establecer la paz firme y duradera en Centroamérica, con base en la Declaración de Esquipulas y el Acta de Contadora para la paz y la cooperación en Centroamérica. ${ }^{12}$

Es decir, que la primera generación de reformas electorales en Centroamérica se da en el contexto de las guerras civiles y con el objetivo de crear condiciones adecuadas para la realización de elecciones justas y competitivas que permitieran a todas las fuerzas políticas disputar el ejercicio del poder mediante la vía electoral y abandonar las luchas armadas.

Esquipulas II abrió ese marco de posibilidades habilitando el retorno de los exiliados y garantizando a los líderes de las organizaciones políticas no armadas su inserción en los procesos electorales. En ese marco regresan los dirigentes de la Contra a Nicaragua y los del Frente Democrático Revolucionario (FDR) a El Salvador, encabezados por Guillermo Ungo, para participar en los procesos electorales que se aproximaban.

\section{Protocolo de Tikal y consolidación de organismos electorales en Centroamérica}

Para entonces, y a inicios de 1980, se había creado el Instituto Interamericano de

\footnotetext{
12 El Acuerdo de Esquipulas II definió un número de medidas para promover la reconciliación nacional, el final de las hostilidades, la democratización, las elecciones libres, el término de toda asistencia para las fuerzas militares irregulares, negociaciones sobre el control de armas y la asistencia a los refugiados. El Acuerdo de Esquipulas I había sido elaborado con base en los trabajos del Grupo de Contadora y sometido a consideración de los presidentes centroamericanos en mayo de 1986, pero fue rechazado por los Estados Unidos de América, argumentando el carácter antidemocrático del Gobierno sandinista presidido por Daniel Ortega.
} 
Derechos Humanos, IIDH, mediante un convenio entre la Comisión Interamericana de Derechos Humanos y el Gobierno de Costa Rica. En 1983 el IIDH creó un programa especializado en temas electorales denominado Centro de Asesoría y Promoción Electoral (CAPEL) que inició sus labores en 1985 bajo la dirección del jurista guatemalteco Jorge Mario García Laguardia, quien con su visionario liderazgo y el apoyo del presidente del Tribunal Supremo Electoral de Guatemala, Arturo Herbruger, organizó en septiembre de ese mismo año la Asociación de Organismos Electorales de Centroamérica y el Caribe, integrada por las máximas autoridades electorales de la región, quienes por haberse reunido en la monumental e histórica ciudad de Tikal, bautizaron el acta constitutiva como Protocolo de Tikal, ${ }^{13}$ dando origen a una iniciativa que serviría para que los organismos electorales de otras regiones se agruparan con los mismos propósitos.

Siguiendo el ejemplo centroamericano, en 1989 se conformó la Asociación de Organismos Electorales de América del Sur, conocida como Protocolo de Quito, y en 1991 ambas asociaciones constituyeron la Unión Interamericana de Organismos Electorales (UNIORE), instancia que posteriormente se amplió con el ingreso de organismos electorales de América del Norte.

\section{El Protocolo de Tikal:}

Se funda en un momento en que la democracia, en proceso de

13 Los organismos electorales fueron estas: la Oficina de Elecciones de Antigua y Barbuda, el Tribunal Supremo de Elecciones de Costa Rica, el Tribunal Supremo Electoral de El Salvador, el Tribunal Supremo Electoral de Guatemala, el Tribunal Nacional de Elecciones de Honduras, el Comité Asesor Electoral de Jamaica, el Consejo Supremo Electoral de Nicaragua, el Tribunal Electoral de Panamá, la Comisión Estatal de Elecciones de Puerto Rico, la Junta Central Electoral de República Dominicana y la Oficina Electoral de Santa Lucía. recuperación en las Américas, todavía parecía incierta, por lo cual el Protocolo de Tikal resulta un espacio de solidaridad y apoyo recíproco entre las instancias encargadas de hacer elecciones. Como consecuencia, marca el inicio de procesos de consolidación institucional, lo cual termina siendo de la mayor importancia para la estabilidad democrática y resulta un adelanto de lo que vendría a ser la "segunda generación" de reformas que buscan apuntalar la democracia en América Latina. ${ }^{14}$

Las reformas electorales de primera generación son el resultado de los compromisos de las partes beligerantes y las condiciones generadas por los Estados en las nuevas normativas constitucionales para garantizar el desarrollo de procesos electorales justos y competitivos. Ello significaba sustituir a los viejos organismos electorales, incondicionales servidores de las dictaduras militares. Por eso, en la región, en la actualidad y con la sola deshonrosa excepción de Nicaragua, las autoridades electorales gozan de un amplio prestigio social y de la confianza de los ciudadanos.

Pero acompañado a ese cambio institucional en la administración de los procesos electorales, hubo que hacer otros ajustes mayores a los sistemas electorales; uno de ellos fue la creación de registros electorales que, aprovechando las nuevas tecnologías, se mantuvieran en constante depuración y actualización.

14 Presentación. Conmemoración del XXV aniversario de la Asociación de Organismos Electorales de Centroamérica y el Caribe, Protocolo de Tikal. Secretaría Ejecutiva Centro de Asesoría y Promoción Electoral. Instituto Interamericano de Derechos Humanos. Tegucigalpa, Honduras. 
Para la época que estamos mencionando, solo Costa Rica podía presumir de un registro electoral confiable y centralizado.

En el resto de países existía dispersión y falta de coordinación entre los registros civiles que manejaban las municipalidades, y los registros electorales asignados a los organismos electorales y, en el peor de los casos, como la Nicaragua de los 80, no existían registros electorales, por lo que en cada elección había que elaborar uno provisional.

El rol de CAPEL, en calidad de Secretaría Ejecutiva del Protocolo de Tikal, fue clave para brindar asistencia técnica en esta materia. Expertos de varias nacionalidades llegaban a los organismos electorales a compartir experiencias, y el intercambio dentro de una política de cooperación horizontal fue más que fructífero en esta materia.

Así, se inició una serie de capacitaciones in situ o mediante visitas programadas al personal de los organismos electorales y se organizaron los cursos interamericanos de Elecciones y Democracia que, programados sistemáticamente, se han constituido en verdadero espacio de reflexión académica e intercambio de experiencias prácticas entre juristas, políticos y politólogos, administradores y funcionarios electorales; llenando además, con los trabajos presentados, un vacío bibliográfico en temas tan especializados como los que presenta la materia electoral. También se logró, en esta etapa inicial, generar una doctrina electoral regional a partir de las conferencias del Protocolo de Tikal, donde los funcionarios del más alto nivel de los organismos electorales discutieron temas estructurales que sirvieron de andamiaje doctrinario y de derecho comparado para la siguiente generación de reformas.

Vale la pena enlistar en este apartado el inicio de las misiones de observación electoral entre los miembros del Protocolo de Tikal. Pero CAPEL tuvo un radio de acción más amplio y pudo observar desde ese periodo los procesos electorales en el Sur de América, desde la misión que se envió a las elecciones de Bolivia en 1985, luego al emblemático plebiscito chileno de 1988, hasta las elecciones en medio de la guerra en El Salvador en 1985, 1988, 1989 y 1991.

El valor de los informes de las misiones de observación fue siempre relativo, pues además de señalárseles como misiones de "turismo electoral" no podían presentar verdaderas evaluaciones de los procesos, ya que asistían exclusivamente a observar el desarrollo de la jornada electoral el día de las elecciones. Pero a partir justamente de esas deficiencias, otras instituciones internacionales creadas en esos días como el National Democratic Institute for International Affairs (NDI), de los Estados Unidos, la International Foundation for Elections Systems IFES o el Centro Carter, pudieron destacar misiones de observación electoral de largo plazo.

\section{Transiciones democráticas y reformas de segunda generación}

Se puede afirmar que el inicio de las transiciones democráticas en la convulsionada región centroamericana se dio con la participación de la izquierda democrática en las elecciones presidenciales de El Salvador en 1989, con la candidatura de Guillermo Ungo, por la Convergencia Democrática, en las que triunfó la opositora y conservadora Alianza 
Republicana Nacionalista (ARENA), así como la entrega de la presidencia de un civil a otro, ${ }^{15}$ hecho político que no se observaba en el país desde 1931, cuando se derrocó al presidente Arturo Araujo y se instauró la dictadura militar.

El otro hecho relevante en esta transición democrática fue cuando el Frente Sandinista de Liberación Nacional perdió las elecciones generales en Nicaragua en 1990 y entregó el poder a la coalición opositora que postuló a Violeta de Chamorro. Ante aflictivos momentos de crisis poselectoral, donde el FSLN no esperaba una derrota ${ }^{16}$ y no se había preparado ni sicológica ni políticamente para ella, la tensión fue muy fuerte. La mediación del presidente Jimmy Carter jugó un papel importante y la dirección del Frente aceptó los resultados, marcando un hito histórico en el que se registraba el hecho de que una fuerza política que había tomado el poder por la vía armada, lo entregaba como resultado de un evento electoral.

Se abría un nuevo ciclo de restauración democrática en la región, en el que las elecciones se legitimaban como el medio idóneo para la disputa del ejercicio del poder político, por lo tanto había que trabajar en la profundización y la modernización de los procesos electorales.

Una segunda generación de reformas electorales se fue creando en los países del istmo. El marco institucional de Centroamérica se actualizó con la firma del Protocolo de Tegucigalpa de 1991, mediante el cual se recreaba una nueva institucionalidad 15 El presidente José Napoleón Duarte, de la Democracia Cristiana, le
entregó la presidencia al electo Alfredo Cristiani, de ARENA.

16 Todas las encuestas daban el triunfo de manera absoluta al FSLN. democrática, con órganos fundamentales como las cumbres presidenciales, la Corte Centroamericana de Justicia, el Parlamento Centroamericano y la Secretaría General del Sistema de Integración Centroamericano.

La región se preparaba para insertarse en el nuevo mundo globalizado, donde Europa, con el Tratado de Maastrich, anunciaba su acelerado proceso de integración y demandaba de sus futuros socios en Centroamérica el cumplimiento de ciertos valores democráticos, cuyos parámetros se fijaban en el respeto a los derechos humanos y, por supuesto, las prácticas democráticas que contienen los ejercicios electorales periódicos, justos y transparentes.

Una vez aceptados los procesos de paz que desmontaron las maquinarias de guerra en la región, tanto las que se dieron entre los Estados (no declaradas pero activas) por interpósitas fuerzas irregulares como los conflictos armados internos que redujeron el papel de los partidos políticos a un protagonismo de tercer orden, estos volvieron a cobrar su perfil social.

La confianza que la sociedad les devolvió a los procesos electorales, los cuales se vieron legitimados por actitudes como la entrega del poder por parte del FSLN o la erradicación de los fraudes electorales en El Salvador durante las elecciones de esta década, constituyó la mejor oportunidad que nunca antes habían tenido los partidos políticos de la región en este siglo, para afianzar su papel de intermediarios legítimos y conductos idóneos para la representación popular.

Sin embargo, sus prácticas antidemocráticas, los escándalos de corrupción, la falta de ética en el ejercicio del poder público, su 
incapacidad técnica para gobernar, dada la ausencia de un servicio civil profesional y el abuso en el clientelismo, la resistencia a la fiscalización de sus finanzas y su rechazo al principio de rendición de cuentas son, entre otras, las causas que les están haciendo perder ese capital político heredado de las luchas que sostuvieron las juventudes democráticas y revolucionarias en las décadas de los 60 y 70.

Con esos antecedentes resulta más fácil comprender por qué algunas de las funciones básicas de los institutos políticos se encontraban (y aún se encuentran) en crisis. Por ejemplo, la representación que es casi la razón de ser de los partidos, está duramente cuestionada, entre otras, por las razones que señala Juan Méndez: "la incapacidad de las instituciones políticas para realizar eficiente y eficazmente sus funciones. La excesiva burocratización y crecimiento desmedido de los aparatos estatales, la corrupción manifiesta en diversos estratos de la manifestación pública y los bajos niveles de participación y control que tiene la sociedad sobre las instituciones políticas, son algunas de las manifestaciones actuales de esa falta de legitimidad política". Agrega Méndez que otro factor es la percepción que tiene la opinión pública de los partidos como maquinarias electorales y no como organizaciones representativas de corrientes de pensamiento, lo mismo que su falta de crecimiento cualitativo. ${ }^{17}$

En cuanto a la crisis en su papel de intermediarios entre la sociedad civil y la sociedad política o Estado, considero que lo que ha sucedido es una deformación del concepto y una derivación a prácticas corruptas.
La mediación como concepto tradicional otorgaba a los institutos políticos la capacidad de interlocución con el Estado en sus diferentes instancias. Eran los partidos, especialmente los de oposición, los que se adjudicaban esa función de interceder por sus bases ante los Gobiernos, para la consecución de algunas reivindicaciones o negociar con el partido oficial cuotas de influencia para el desarrollo de algunas actividades en favor de sectores, comunidades o grupos sociales excluidos de los proyectos gubernamentales.

En cuanto a los partidos oficiales, siempre usaron esa capacidad de influir en los planes y programas de Gobierno para mantener el clientelismo político que les garantizara resultados electorales favorables.

El concepto como tal se fue deformando tanto por esas mismas prácticas viciadas que la opinión pública comenzó a identificarlas como gestiones en provecho propio de los partidos, de sus dirigentes o sus círculos próximos; al extremo de que otros sujetos fueron asumiendo el papel de intermediación con mayor eficacia. Entre estos sujetos están sin duda los medios de comunicación, los cuales, con el giro que tuvieron los espacios informativos, los programas de opinión, el periodismo investigativo, los servicios a la comunidad entre otros, se volvieron efectivos canales para pedir, denunciar, reconocer, evaluar etc. a los funcionarios públicos, la prestación de los servicios del Estado, la gestión de los municipios, legislaturas, tribunales y demás órganos y funciones del Estado.

Es curioso que en la mayoría de las encuestas de opinión en materia de confianza social y política, los medios de comunicación 
encabecen las preferencias y los partidos se encuentren en los últimos lugares. Surgieron también otros sujetos como las ONG, algunas instituciones religiosas, académicas y comunitarias que vinieron a reemplazar a los partidos políticos con mucha más eficiencia, dada la especificidad de sus áreas de trabajo, su autonomía frente al poder público, su ausencia de compromisos con el sistema político, en fin, su mayor libertad de acción y expresión. Todo lo anterior se expresó en exigencias y demandas ciudadanas de mayor participación en los procesos electorales, abriéndose avenidas para el surgimiento de outsiders exitosos como Fujimori, Aristide y más tarde el propio Chávez en Venezuela. También se dio paso a una demanda de reformas en el financiamiento de la política y la exigencia de transparencia en el manejo de los fondos partidarios. Varios foros regionales y continentales de discusión sobre este tema fueron iluminando las futuras legislaciones que en cada uno de los países se regulaba de manera diferente.

La buena noticia es que los jefes de Estado y de Gobierno de los países del Sistema de la Integración Centroamericana (SICA), reunidos el día 15 de noviembre de 2006 en la ciudad de Guatemala, República de Guatemala, en ocasión de la $12 .{ }^{\text {a }}$ Conferencia Internacional Anticorrupción, firmaron la DECLARACIÓN DE GUATEMALA PARA UNA REGIÓN LIBRE DE CORRUPCIÓN y se comprometieron en el numeral 12 a "Promover la adopción de las normativas que establezcan sistemas de control para el financiamiento electoral y político".

Un compromiso y una reforma que continúan pendientes de profundización y exacto cumplimiento, pero que la presión social y la auditoría ciudadana siguen exigiendo. Por suerte, en este periodo hicieron su aparición en la escena política varios organismos internacionales que, mediante mecanismos de asistencia electoral, fueron elevando los estándares de calidad en materia de administración electoral, desempeño de los partidos políticos y de las organizaciones de la sociedad civil que participaban en la política y específicamente en los procesos electorales.

Al inicio fueron los organismos multilaterales como Naciones Unidas y la OEA los que por el carácter estatal de su membresía lograron continuar trabajando en los temas electorales después de finalizados los conflictos militares. Posteriormente, se habilitó la participación de organizaciones no gubernamentales internacionales como NDI, Centro Carter, IFES, IDEA International, así como de algunas fundaciones europeas afiliadas a las internacionales, como las alemanas Friedrich Ebert, Konrad Adenauer, etc.

\section{Democracias insuficientes y reformas de tercera generación}

A pesar de los avances obtenidos en la transición hacia la democracia que se inició hace unas décadas, América Central se encontró en un momento crítico que urgía de reformas en los sistemas políticos. Las causas de la frustración con los modelos democráticos, entre otras, se le asignaban a las formas en que se ha accedido a la representación; así como al desempeño, no siempre satisfactorio, de los electos.

Una de las razones que se externaron para mostrar este desencanto señalaba la dependencia casi absoluta del ejercicio de la política en relación con el dinero. Era innegable la influencia que los grandes 
contribuyentes ejercían (y aún ejercen) en los resultados electorales, con las consecuencias por todos conocidas. También hubo quejas por el uso indebido de recursos del Estado, por la falta de transparencia y publicidad en las finanzas partidarias, por la ausencia de límites en los gastos electorales que encarecen la política y arriesgan la equidad en la contienda electoral, etc.

A los medios de comunicación social también se les cuestionó su independencia e imparcialidad no solo porque en sus líneas editoriales manifestaron abiertamente su simpatía por determinado partido político o candidato, sino también por la sesgada cobertura informativa sobre hechos políticos o en las campañas electorales. Se llegó al extremo de tergiversar realidades o dar crédito y publicar rumores infundados, citando "fuentes dignas de todo crédito" para favorecer o perjudicar a una u otra opción política.

Por otra parte, Latinobarómetro mostró sistemáticamente el descontento ciudadano con los logros de estos modelos democráticos; puesto que los países no habían alcanzado el crecimiento económico prometido, el desempleo campeaba en la región dejando como la salida más viable la emigración hacia los Estados Unidos, el combate a la pobreza no pasaba de unos cuantos programas sociales insostenibles por sí mismos y con una inspiración claramente asistencialista. Para cerrar este círculo de frustración, el incremento de la violencia cotidiana y el accionar de las pandillas que se multiplicaban en Guatemala, Honduras y El Salvador generaban un esquema de inseguridad ciudadana que el Estado no supo contener, especialmente porque privilegió políticas represivas como la de "mano dura y súper mano dura".

Todo lo anterior fue caracterizado como democracias insuficientes, y mientras desde las instancias del Estado se buscaban desesperadamente soluciones, en la sociedad se añoraban regímenes autocráticos que en el pasado fueron capaces de mantener "el orden público y la paz social".

En el nivel político y electoral el debate por garantizar contiendas más equitativas, seguras y justas se movía hacia una tercera generación de reformas. El mejoramiento de los marcos institucionales para asegurar canchas niveladas y reglas claras, afinando los controles del financiamiento político, especialmente el de origen privado, y la incorporación de nuevas tecnologías a los procesos eleccionarios, fueron signos de este periodo.

El cuadro 1 muestra una visión comparativa sobre los órganos de control en la región en aquel periodo.

En cuanto a la introducción de nuevas tecnologías a los procesos electorales, Centroamérica no ha alcanzado aún el voto electrónico que se ensayó en Brasil en 1996, tampoco las máquinas "capta huellas", utilizadas en Venezuela desde 2004, pero sí evolucionó en el tema de los documentos de identidad personal y electoral.

Los Estados han aprovechado los avances tecnológicos para mejorar sus sistemas registrales y producir documentos de identificación cada vez más seguros. Desde la modesta plastificación que se 


\section{Cuadro 1: Órganos encargados del control y aplicación de las normas}

\begin{tabular}{cr}
\hline País & Órgano de control \\
\hline Costa Rica & Tribunal Supremo de Elecciones (Órgano Electoral) con la participación de la Contraloría \\
General de la República.
\end{tabular}

1 Aunque en la práctica -y hasta la fecha- nunca ha realizado dicho control.

2 Organismo temporal. Seis meses antes de cada elección, plebiscito o referendo, se debe de crear dentro de la Procuraduría General de Justicia, una Procuraduría Específica Electoral que cesará en sus funciones una vez resueltos los problemas correspondientes. Art. 178 LE.

utilizó para su protección física, hasta indestructibles materiales producto de fusiones moleculares, se han ensayado. La adopción del documento más seguro depende también de los recursos con que se cuente. En la actualidad, la fotografía, la firma, los sellos de la autoridad electoral, su cobertura plástica y otros rudimentarios mecanismos de seguridad, tienden a ser sustituidos por tecnologías como el sistema AFIS (Automated Fingerprint Identification System), hologramas, códigos de barra y los más avanzados que incluyen un microprocesador capaz de almacenar una hoja de vida completa de su titular. ${ }^{18}$

También se avanzó en esta etapa en anunciar provisionalmente los resultados el mismo día de las elecciones. Ante la incertidumbre que generaba el desconocimiento del ganador en el pasado, con la implementación de los conteos rápidos no solo se le brinda a la población la información que en todos los casos coincide con el resultado final que anuncia la autoridad electoral varios días después de la elección, una vez evacuadas las impugnaciones; sino que también se evita cualquier manipulación del resultado por operadores mal intencionados. Con base científica se elabora el software que maneja el proceso, se diseñan los formularios que llenarán los voluntarios de la red de observadores previamente capacitados y desplazados a los puntos que constituyen la muestra y que son centros de votación seleccionados al azar por el programa.

Transmitidos los resultados oficiales por cada uno de los observadores asignados, el equipo que está analizando los datos, una vez estabilizada la muestra, es capaz de concluir y determinar quién aventaja en la contienda y con una tendencia irreversible. 
Todos los países de la región han implementado este proyecto, generalmente con el NDI, aunque OEA y otros organismos también los ejercitan.

\section{La primavera democrática en América Latina y el socialismo del siglo XXI}

Estábamos por terminar el siglo XX cuando se celebraron las elecciones presidenciales en Venezuela en 1999, las cuales ganó el presidente Hugo Chávez. Fue un evento histórico que marcó un giro de $180^{\circ}$ en la política del continente, que sin duda tendría efectos en la región. Luego vendrían otros procesos electorales en los que triunfarían sindicalistas como Lula en Brasil y Evo Morales en Bolivia, el exobispo Lugo en Paraguay, la exiliada política Michelle Bachelet en Chile, el economista Correa en Ecuador, Kirchner en Argentina, un exguerrillero Tupamaro en Uruguay, volvería a gobernar Ortega en Nicaragua, y para finalizar la década en 2009, ganaría el FMLN con el periodista Mauricio Funes en El Salvador.

El signo ideológico de esta variopinta lista de mandatarios cambió el rostro del subcontinente $y$, sin duda, las agendas definidas por la doctrina del Consenso de Washington de las décadas anteriores se modificarían drásticamente. La confrontación ideológica-política de la Guerra Fría, que se llevó al campo militar por las insurgencias apoyadas por Cuba y la URSS, cambiaba de escenario y de actores, pues las batallas se libraron en las arenas electorales, los protagonistas fueron los partidos y los líderes políticos, y quien finalmente decidió fue el electorado libre y debidamente informado. A este fenómeno se le dio en llamar la primavera democrática de América Latina.
Para algunos como Dussel, "Hay una cierta primavera política que nunca había acontecido. Hay un crecimiento. Creo que hemos comenzado el proceso de la segunda emancipación. Estamos elaborando las teorías y viviendo las primeras grandes experiencias de una América Latina que por fin empieza a situarse en igualdad con los otros bloques históricos que están surgiendo". ${ }^{19}$

Otros, como Monsant Aristimuño, replantean el concepto así:

Lo cierto es que el término primavera política, nació con la explosión de un ¡basta; en el Líbano, luego en Egipto, Libia, Yemen y ahora en Siria, y no es otra cosa que la rebelión de un pueblo, del pueblo llano cansado de autocracia, arbitrariedad, represión, corrupción, ausencia de libertad individual que, en nombre de una ideología, partido, religión o dinastía mantenía y mantiene al ciudadano bajo su arbitrio, criterio y dominio. Ese despertar, esa primavera de Nuestra América se inició en El Salvador con la elección de Mauricio Funes que marcó un hito en la historia del país, candidato independiente de un partido radical, marxista y guerrillero, entendió que sus votos significaban una esperanza de paz, trabajo, respeto e igualdad ante la ley. ${ }^{20}$

Pero algunos han pretendido caracterizar este fenómeno como socialismo del siglo XXI, un concepto atribuido a Heinz Dieterich Steffan, que sigue siendo etéreo y confuso como para actualizar -y menos aún sustituir- la clásica doctrina marxista basada en métodos científicos de interpretación 
histórica. Sin embargo, si se considera, como dice Dieterich, que no pretende plantear un modelo único y absoluto para lograr una sociedad democrática, participativa, socialista y sin clases sociales, "sino más bien establece una metodología para elaborar lo que denomina El Nuevo Proyecto Histórico cuyos pilares estratégicos son el Bloque Regional de Poder (BRP) que sería la integración económica y política de los Estados Progresistas de la región y el Bloque Regional de Poder Popular (BRPP) que correspondería a la coordinación continental de los movimientos sociales que apoyen a la implementación del Socialismo del siglo XXI".

Al margen de las discusiones que el fenómeno pueda generar entre los intelectuales, lo importante es evaluar sus resultados. Sabemos que por la diferencia de tiempos en que se han sucedido estos cambios de Gobierno -y en algunos casos de régimen- y más aún, porque la Ley del Desarrollo Desigual y Combinado nos condiciona a no sacar conclusiones generalizadas, nos detendremos únicamente en aquellas que pueden ser afines al tema que tratamos, el cual es eminentemente electoral y circunscrito al ámbito de nuestra región centroamericana.

Las instituciones de la democracia directa no son una creación de los países miembros de la Alianza Bolivariana para los Pueblos de Nuestra América-Tratado de Comercio de los Pueblos, conocida como ALBA. El pensamiento conservador de la región ha visto con recelo el uso de estas instituciones, especialmente el referendo, como un mecanismo de reforma constitucional para prolongar el mandato de los presidentes en varios países del sistema ALBA, Ilegando incluso en el caso de Venezuela a consignar la reelección indefinida.

Frente a esa realidad, nuestra opinión es que la reelección no es mala ni buena, que nuestra América la considera de diferentes maneras, tal es el caso de México, Honduras, Paraguay o Guatemala, donde está prohibida en todas sus formas, o El Salvador, Chile, Costa Rica y Perú, entre otros, que la permiten de manera alterna. Por otra parte, el único caso además de Venezuela que ha aprobado la reelección indefinida es Nicaragua, donde no se utilizó el mecanismo del referendo para tal fin, sino un fallo de la Corte Suprema de Justicia en 2011 que, frente a un recurso de amparo del presidente Ortega lo habilitó para presentarse a un tercer mandato, declarando inconstitucional el artículo de la Constitución nicaragüense que lo prohibía. Habiendo ganado las elecciones de noviembre de 2011 y con una mayoría absoluta en la Asamblea Nacional, el FSLN aprobó la reforma constitucional que reconoce el derecho del presidente a ser reelegido indefinidamente.

Sobre este tema, quisiéramos recordar el caso del presidente George Washington, quien no obstante de que la Constitución no lo prohibía y al ser propuesto para un tercer periodo, después de su reelección, la declinó en estos términos:

Amigos y conciudadanos: Nunca me ha parecido más oportuno el manifestaros la resolución que tomé de separarme del cargo que ocupo, como en las circunstancias actuales, cuando ya se acerca la fecha de elegir al nuevo depositario del Poder Ejecutivo de los Estados Unidos y ha llegado el momento de resolver a 
quién debéis confiar tan importante comisión. Y a fin de que la emisión del voto sea libre y expeditiva por entero, debo anunciaros que no figuraré yo entre los candidatos sobre quienes ha de recaer vuestra elección. Os suplico que me dispenséis la justicia de creer que no he tomado esta resolución sin haber tenido muy en cuenta las obligaciones que corresponden a un ciudadano sumiso al interés de su patria, y que la determinación de retirarme no implica merma del celo por vuestros intereses futuros, ni es falta de gratitud a vuestra constante bondad, sino tan sólo un efecto del pleno convencimiento que tengo de que este paso no es incompatible con aquellos objetos...22

O más contundente aún, nuestro epónimo libertador Simón Bolívar, en el histórico discurso de Angostura el 15 de febrero de 1819:

La continuación de la autoridad en un mismo individuo frecuentemente ha sido el término de los gobiernos democráticos. Las repetidas elecciones son esenciales en los sistemas populares, porquenadaestan peligroso como dejar permanecer largo tiempo en un mismo ciudadano el poder. El pueblo se acostumbra a obedecerle y él se acostumbra a mandarlo; de donde se origina la usurpación y la tiranía. Un justo celo es la garantía de la libertad republicana, y nuestros ciudadanos deben temer con sobrada justicia que el mismo magistrado, que los ha mandado mucho tiempo, los mande perpetuamente". ${ }^{23}$
Pero, retornando al tema de las instituciones de la democracia directa, la doctrina contemporánea las conceptúa de manera diferente en sus formas actuales de cómo se presentaban en la antigua Grecia al indicarnos cómo sus instituciones juegan un papel fundamental en la formación de la voluntad política y sus procedimientos.

Como indica Thibaut, estas instituciones van asociadas con las funciones de integración social y aumento del consenso político. Para dar una idea de esa diferenciación, trabajamos con el concepto de instituciones de la democracia directa en los siguientes términos: “...aquellas formas de participación política que se realizan con el voto directo y universal, pero que no consisten en seleccionar a los miembros de los órganos democrático-representativos, sea el legislativo o el ejecutivo". ${ }^{24}$ Entre ellas podemos mencionar las más conocidas y difundidas como son el plebiscito y el referéndum. Sin embargo, algunas legislaciones constitucionales han dado paso a nuevas instituciones como la revocatoria del mandato y las iniciativas ciudadanas.

Se ha publicitado suficientemente la naturalezademocráticadelosEstadosUnidos de América, poniéndola generalmente como paradigma de la democracia representativa, y los conservadores la enarbolan como antagónica a la democracia participativa que, según ellos, es el modelo que incorpora las instituciones de la democracia directa.

Pues, para dejar claro ese falso dilema en el cual optar por la democracia representativa es rechazar las cuatro instituciones arriba mencionadas, les recordamos que en los Estados Unidos de América, la Iniciativa Ciudadana fue introducida desde 1715, 
iniciándose en el estado de Massachussets, cuyos electores la han utilizado desde ese año. Posteriormente se adoptó en Dakota del Sur en 1898. En la actualidad, 23 constituciones estatales autorizan el uso de peticiones para colocar propuestas de los ciudadanos en la papeleta.

En cuanto a la revocatoria del mandato legislativo o destitución de funcionarios por medio de los votos, existen disposiciones constitucionales y estatutarias en 26 estados de los Estados Unidos que autorizan a los votantes a pedir la destitución de todos o algunos funcionarios públicos, antes de la finalización de su periodo, introduciendo la pregunta respectiva en la papeleta de un referéndum. Adicionalmente, las municipalidades de ciertos Estados pueden elaborar proyectos de nuevas normativas o enmiendas a la legislación vigente, permitiendo la revocatoria del mandato. Para otros que carecen de esta facultad constitucional, la legislatura estatal ha promulgado normas especiales autorizando la destitución de funcionarios de gobiernos locales por medio del voto. 25

En cuanto al referéndum y el plebiscito, son figuras más conocidas y de hecho consideradas en algunas de las legislaciones de la región. Sin embargo, vale la pena advertir sobre el uso abusivo (o mal uso) de este. Como hace notar Michael Gallagher: "Hay muchas formas en las que un referéndum puede ser mal utilizado, aún más, abusado. Y abundan estos casos. En Francia, por ejemplo, un alto número de referéndum sostenidos desde la Segunda Guerra Mundial fueron realizados por razones políticas oportunistas, cuando el gobierno vio la oportunidad de humillar o dividir a la oposición". ${ }^{26}$ El plebiscito también consiste en una consulta directa al cuerpo electoral, pero no sobre una decisión legislativa, sino sobre algún asunto de excepcional importancia para la comunidad, que puede comprometer su futuro.

Alguna doctrina, lo mismo que el estudio de cierta legislación comparada, nos muestran la confusión del referéndum con el plebiscito. La diferencia esencial consiste en que este último no afecta a actos de naturaleza normativa, se refiere a cuestiones de hecho, actos políticos y medidas de Gobierno. Especialmente afecta cuestiones de carácter territorial y a materias relativas a la forma de Gobierno y su ejercicio. Además, la voz plebiscito tiene su origen en el término latino plebiscitum. Era el llamado o convocatoria a la "plebe", al pueblo Ilano durante la República romana; en tanto referéndum, viene del vocablo latino referre o sea referir. En América Latina, dice Juan Rial, para finales de la década de los 90, trece países regulaban a nivel nacional diferentes mecanismos de democracia directa en sus respectivas Constituciones.

Retomando el papel que juegan los partidos políticos en la activación de estas instituciones en la actualidad, vemos que es muy diferente a su esfuerzo por alcanzar las cuotas de representación, realizado en las contiendas electorales, dentro de las democracias representativas. Por regla general se involucran activamente en su dinámica $y$, aunque los fines son completamente diferentes, los procedimientos técnicojurídicos y organizacionales en las consultas populares y en los procesos electorales son básicamente los mismos. Es más, en algunos estados de los Estados Unidos de América se mezclan ambos sistemas, 
pues en el mismo día de las elecciones (en la misma boleta, en algunos casos) se le presenta al elector la posibilidad de decidir una enmienda constitucional, la revocatoria del mandato de un funcionario (recall) o la petición de un grupo representativo de la sociedad, sobre un tema trascendental de política pública (iniciativa ciudadana). Por ello, se afirma ahora, las instituciones de la democracia directa no son formas contrapuestas de organización política, versión que se fundamentaba según Thibaut "en la dicotomía clásica entre la idea de Sieyes y otros, de que la soberanía popular sólo puede realizarse mediante la representación política, por un lado, y la idea asociada con Rousseau de que la soberanía popular no es trasladable, por otro". ${ }^{27}$

Tampoco constituyen una alternativa básica para los modelos democráticos, sino un complemento más o menos puntual de los procesos de decisión organizados de manera democrático-representativa. ${ }^{28}$

\section{Los desafíos para el siglo XXI}

Comenzamos la segunda década del siglo XXI conmás déficits quelogros en la construcción de una sociedad que proporcione una convivencia armónica y solidaria para nuestros pueblos. A pesar de las grandes promesas y oportunidades que nos brindó el siglo XX, fueron caudillos mesiánicos, dictadores despóticos o ilustrados, castas corruptas e incapaces quienes gobernaron nuestras repúblicas durante todo ese periodo. Raros y excepcionales momentos fueron ocupados por estadistas demócratas y visionarios. Como diría Octavio Paz, esta visión hipercrítica nuestra se caracteriza por el síndrome de los dos fantasmas: el del tiempo cíclico y el de la imperfección.
Por ello, sin ser benevolentes ni gratuitos con nosotros mismos, debemos reconocer con el informe de Latinobarómetro de octubre 2011 que:

La primera etapa de construcción de la democracia ya está terminada. Esa fue la recuperación de las libertades civiles, que hoy están mayoritariamente garantizadas según evidencian nuestros datos. [...] América Latina ahora está demandando igualdad, las garantías sociales[...]. Mientras en los primeros años la demanda era la consolidación de las libertades, hoy dominan las demandas de la igualdad de oportunidades..." y continúa sosteniendo: "Las elites estaban preparadas para asegurar, garantizar las libertades civiles, otra cosa es estar preparados para garantizar los derechos sociales. Ello requiere del desmantelamiento no de elites políticas, sino más bien de culturas de dominación centenarias, estructuras de poder y estilos de interacción. El proceso de transformación societal que se requiere para las garantías sociales es mucho más profundo que el que se requería para las garantías civiles. ${ }^{29}$

Desde luego que la Centroamérica de hoy tiene rasgos muy distintos a los que tuvo cuando se desmontaron los conflictos de los 80 y se iniciaron las transiciones democráticas. La configuración actual refleja otro tipo de conflictos tan brutales y sangrientos como los de aquella época. ¿Qué pasó entonces en esta región? ¿Cómo fue posible que las élites dominantes no pudieran prever los efectos que anunciaba la sociedad posconflicto donde los grupos militares y paramilitares, desempleados, 
excluidos y marginados en el modelo de acumulación económica recomendado por el Consenso de Washington, pero armados y organizados, lógicamente optarían por otro tipo de violencia, en el marco de las pandillas y el crimen organizado?

Esta nueva variable hay que considerarla como una pandemia que azota la región con saldos trágicos superiores, en algunos casos, a los que sufrimos durante las guerras civiles de las décadas de los 70 y 80 del siglo pasado, según Peter Hakim quien nos advierte que:

Alrededor del $27 \%$ de la población de la región identificó la delincuencia como el mayor problema que debió enfrentar su país en 2010, por sobre cualquier otro problema, incluyendo la economíayel desempleo, queporlargo tiempo fueron las preocupaciones dominantes. La delincuencia y la seguridad pública fueron identificadas como el principal problema en 11 de los 18 países encuestados. Este imaginario entre los ciudadanos comunes no sorprende, pues no hace más que reflejar la creciente violencia que existe en sus naciones y la penetración cada vez mayor del crimen organizado en América Latina y el Caribe. En comparación con otras regiones del mundo, en América Latina las tasas de homicidios han sido tradicionalmente altas, sin embargo han aumentado drásticamente en la última década y actualmente sólo son superadas por las tasas observadas en los Estados africanos devastados por la guerra. Cinco naciones de América Latina y el Caribe (El Salvador, Venezuela,
Jamaica, Guatemala y Honduras) se encuentran entre los países más violentos del mundo, con tasas de homicidios superiores a 40 por cada 100.000 habitantes, en comparación con una incidencia inferior a 6 por cada 100.000 habitantes en Estados Unidos, 3 en Europa y 2 en China. Además, la delincuencia y la violencia conllevan un alto costo en varios otros aspectos. La cuantificación de estos costos es difícil e imprecisa; sin embargo, las estimaciones apuntan a una cifra superior al $12 \%$ del PIB anual para algunos países y superior al $5 \%$ para la mayor parte de la región. ${ }^{30}$

Vulnerable ante los desastres naturales como terremotos, ciclones, actividad volcánica y demás derivados del cambio climático, Centroamérica enfrenta hoy la seria amenaza de pasar de ser corredor de la droga a convertirse en santuario de los más feroces carteles mafiosos. Pandillas, crimen organizado, debilidad institucional, corrupción y cooptación de importantes esferas del Estado, son los indicadores negativos que refleja la región. Como afirma Zovatto al comentar los datos del informe de Latinobarometro estos: “... evidencian el momento delicado y de pesimismo que atraviesan la mayoría de los países centroamericanos, uno de los más difíciles de los últimos 20 años. A los tradicionales altos niveles de pobreza, exclusión y desigualdad, se le suma una situación de creciente debilidad institucional y el haberse convertido en la región más violenta de América Latina". ${ }^{31}$

En ese contexto poco alentador para enfrentar los desafíos democráticos de este siglo, es siempre saludable recordar 
y tener presente que los países de las Américas optamos a inicio de siglo por el modelo de democracia representativa, comprometiéndonos a su promoción y consolidación en la Carta Democrática Interamericana, suscrita por los 34 países en Lima el 11 septiembre de 2001, y aceptamos implícitamente que serían las elecciones periódicas, libres y justas el mecanismo idóneo para la disputa por la representación en los cargos de elección popular.

Las reglas democráticas para las contiendas por esa representación se han ido perfeccionando en el decurso de la historia y han logrado establecer parámetros más o menos universales que constituyen el fundamento de la democracia representativa; entre ellos destacan el sufragio universal, la igualdad política, la regla de la voluntad de la mayoría con respeto a las minorías, entre otras. Estos referentes los encontramos como piezas claves en los sistemas electorales que son el conjunto de instituciones y procedimientos mediante los cuales, de manera periódica, segura, transparente, equitativa y pacífica, los ciudadanos ejercen el derecho humano y fundamental a elegir y ser electos (Art. 21 Declaración Universal de los Derechos Humanos).

Los sistemas electorales se diferencian de país a país; actualmente existen más de 200 sistemas electorales en el mundo. La riqueza de esta diversidad se explica por las diferentes pautas culturales con las que se diseñan. Sinembargo, todos tienen en común la regulación de los partidos políticos como actores fundamentales en la articulación de la representación política, además de otras funciones como la mediación, la educación cívica, el control y el balance de la gestión pública, etc., de ahí que el desafío inicial, que puede ser la piedra angular en el conjunto de reformas venideras, tenga que ver con el establecimiento de reglas y prácticas democráticas en el interior de los partidos políticos, a fin de garantizar una mejor calidad en la representación popular.

\section{Mejorar la calidad de la representación}

Mejorar la calidad de la representación es una demanda que se escucha en todos los tonos de voces desde las plataformas ciudadanas. Pero muchos partidos se resisten a democratizar los mecanismos internos para la selección de los candidatos a cargos electivos. El dedazo, el compadrazgo y las lealtades personales siguen imperando como criterios de selección, anulando mecanismos de consulta a las bases (asambleas o elecciones primarias). Argumentos como la unidad partidaria o la disciplina consciente campean para justificar esa falta de democracia. Al final, esos mecanismos se trasladan a los sistemas electorales nacionales y el resultado son parlamentos y gobiernos locales integrados por dóciles -y muchas veces incompetentesfuncionarios que sin una responsabilidad directa con los electores siguen ciegamente las instrucciones del partido, aunque estas riñan con los de la comunidad que gobiernan o representan.

\section{Fortalecimiento institucional y modernización de los marcos jurídico electorales}

Desde luego que una mejoría en la calidad de la representación, además de elevar los niveles e índices en la calidad de la gestión, facilita -si no impulsa por sí misma- el fortalecimiento institucional y asegura la modernización de los marcos jurídicos que regulan los procesos electorales. 
Las más recientes elecciones presidenciales en la región, realizadas entre 2009 y 2014 (2012 en República Dominicana), se desarrollaron en un momento de cambios sustanciales que definen el rumbo que están tomando los países. Entre sus indicadores más importantes destacan:

a. Fin del bipartidismo. Con la irrupción de dos fuerzas emergentes LIBRE en Honduras y PAC en Costa Rica, se pone fin al bipartidismo que dominó en ambos países las últimas décadas del siglo XX. Los liberales y conservadores en Honduras y los socialdemócratas y socialcristianos en Costa Rica. Anteriormente y con el triunfo de la revolución sandinista en 1979, ese modelo de bipartidismo decimonónico se había terminado en Nicaragua. Guatemala se ha caracterizado por un sistema disfuncional de partidos, dada su fragmentación y volatilidad, y en El Salvador las dos formaciones que se enfrentaron durante el conflicto ARENA y el FMLN y que se mantuvieron como principales adversarios en la postguerra, por fin enfrentaron una tercera opción en la primera ronda electoral. El movimiento UNIDAD logró captar suficientes votos como para forzar a una segunda vuelta y de no haber sido por causas que no son objeto de este trabajo, pudo haber roto el esquema de polarización que ARENA creó, con el objetivo de eliminar a UNIDAD y quedarse como la única opción de signo conservador para enfrentar al FMLN. Esta nueva realidad que significa una real remoción dentro del sistema de partidos políticos podría ser la oportunidad para avanzar en su democratización y modernización.

b. Los Estados también asumieron algunas de las demandas ciudadanas y las incorporaron a las reformas que hicieron a sus leyes electorales. En El Salvador se aprobó una ley de partidos políticos que finalmente regula, aunque muy tímidamente, el financiamiento privado a los partidos políticos. En Costa Rica se consignó en las reformas de 2009 la paridad de género en los cargos electivos, aunque el resultado electoral del 2 de febrero de 2014 aportó menos mujeres que el sistema anterior, por lo cual tendrán que buscar un nuevo ajuste electoral que garantice la forma de elaboración de listados de candidatos, no solo verticalmente sino tomando en cuenta listados provinciales en sentido horizontal.

En cuanto a Guatemala, son múltiples las iniciativas y sus gestores que buscan reformar el sistema electoral, varias de ellas están encaminadas al fortalecimiento del sistema de partidos, mediante su consolidación y los ponentes de la Iniciativa 3826 entienden que se debe garantizar "diversidad de partidos pero sin llegar a un multipartidismo exacerbado". También existe la Iniciativa 4088 que de ser aprobada, obligaría a que las listas de candidatos estén integradas por indígenas y mestizos en cantidades proporcionales a la conformación étnica de cada distrito electoral; además, hombres y mujeres se alternarán en el orden de postulación. Especial interés se les ha dado a las propuestas para regular el financiamiento de los partidos, así la Iniciativa 4290, del TSE, es más explícita en este sentido y obligaría a los comités ejecutivos nacionales 
receptores de la deuda política a descentralizar los fondos derivados de esta, de acuerdo a proporciones y porcentajes establecidos en la ley.

En Honduras, después de las traumáticas elecciones de 2009, precedidas por el golpe de Estado contra el presidente Manuel Zelaya, el presidente electo Porfirio Lobo creó la Comisión de la Verdad y Reconciliación, coordinada por el exvicepresidente de Guatemala, Eduardo Stein, la cual en su informe presentó un conjunto de 12 recomendaciones de reforma al sistema político, a los partidos políticos, al Tribunal Supremo Electoral (TSE) y al Registro Nacional de las Personas (RNP). Además de estas reformas institucionales, se proponían temas relacionados con las minorías como el voto de los discapacitados, el aumento en la cuota de género para favorecer a las mujeres e incluso el incremento de la deuda política aumentando el valor de cada voto.

El caso panameño es sintomático, pues el gran consenso social y político alcanzado en la Comisión Nacional de Reformas Electorales que se instaló el 14 de enero de 2010, y cuyo proyecto de reformas alcanzaba 97 artículos de la ley electoral, fue sometido a la Asamblea Nacional en enero de 2011. Sin embargo, en el seno de la Comisión de Gobierno de la Asamblea Nacional prevalecieron los limitados criterios y los intereses particulares de los diputados, llevando a la suspensión de su debate por el presidente de dicha Asamblea, del partido Cambio Democrático (CD), del presidente Martinelli. Entre las reformas que contenía el paquete de la CNRE estaban: la libre postulación para presidente y vicepresidente de la República; transparencia en el financiamiento privado y topes a los gastos y a las donaciones; medidas para reducir el costo de las campañas y la saturación de la propaganda electoral; fecha única para las elecciones primarias, respeto a la voluntad popular en las primarias; equidad de género; creación de un circuito plurinominal nacional, voto adelantado para los residentes en el exterior; renuncia de servidores públicos que opten a una candidatura; reducción de porcentaje para la subsistencia de partidos políticos, entre otras, como lo relativo a las encuestas y la exclusión oficiosa del padrón electoral.

Ante el fallido intento panameño, encontramos el exitoso avance dominicano que desde la década pasada continúa con los esfuerzos de modernizar su sistema electoral. Mediante la Ley Orgánica Núm. 29-11 del 20 de enero de 2011, se creó el Tribunal Superior Electoral como máxima autoridad en materia contenciosa electoral, sumándose a los países que tienen el sistema de dos entidades: una que planifica, organiza y ejecuta los procesos electorales, y otra que dirime los conflictos de la jurisdicción electoral. En la República Dominicana, la función administrativa quedó en la Junta Central Electoral creada desde 1923 y que en un afán de separar ambas funciones fue dividida a mediados de la década pasada. Con esta reforma constitucional, así como la extensión de la representación en el Congreso Nacional para la diáspora 
dominicana, este país marca un paso adelante a la región, donde la demanda de representación política por parte de sus poblaciones migrantes, es cada día más fuerte.

c. El voto desde el exterior, ejercitado por primera vez este año 2014 en países como Costa Rica y El Salvador, viene a sumarse a una práctica ya ensayada en la República Dominicana, Honduras y Panamá. Quedan pendientes Guatemala y Nicaragua, que sin duda examinarán las experiencias de los países que les preceden. Con mucho éxito se realiza en la República Dominicana desde mediados de la década pasada (en 2004 votaron en 4 países), al grado de que en estas últimas elecciones de 2012, los dominicanos residentes en el exterior eligieron 7 representantes al Congreso Nacional.

Queda como tarea pendienteel voto delos extranjeros, entendidos estos colectivos como el ciudadano que tiene negocios, domicilio y arraigo en el país huésped y que residiendo legalmente en este, no ha optado por la nacionalidad. Este concepto viene aparejado al fenómeno de las migraciones, que ha cambiado el rostro de la comunidad internacional. Como dijera Baki Moon desde la ONU el 18 de diciembre recién pasado: "Somos más de 200 millones de seres humanos los que vivimos y trabajamos en países que no son los nuestros". Y deberían garantizárseles derechos fundamentales como el sufragio. La nueva realidad del mundo global reconoce el concepto de ciudadanía transnacional, por tanto, es una materia pendiente de regulación en nuestros países expulsores de migrantes, garantizar ese derecho a los extranjeros que radican en nuestros territorios. d. Fortalecimiento de las autoridades electorales. Una de las garantías para un proceso electoral seguro, transparente y confiable ha sido el desempeño de las autoridades electorales. Huelga recordar que uno de los factores que desencadenaron la guerra en El Salvador fueron los escandalosos fraudes electorales de 1972 y 1977, en los cuales su ejecutor fue el Consejo Central de Elecciones, máxima autoridad electoral de la época.

En las nuevas Constituciones centroamericanas, promulgadas en la década de los 80, así como en las reformas posteriores surgidas en los procesos de paz, se tuvo el cuidado de diseñar autoridades electorales con competencias e integración que generaran confianza en la ciudadanía y seguridad en los contendientes.

Excepto en Honduras, donde el Tribunal Nacional de Elecciones era integrado por magistrados nombrados (y destituidos) directamente por los partidos políticos, el resto de los miembros de dichos organismos eran elegidos por los Congresos o Asambleas Legislativas, de listas propuestas por distintas fuentes. En algunos países son propuestos por los poderes públicos; en otros, por los partidos políticos o las universidades. Honduras, a raíz de las reformas de 2004,32 entró en esta corriente y ahora la autoridad electoral se llama Tribunal Supremo Electoral, y sus integrantes son elegidos por el Congreso.

32 Mediante reformas a la constitución de fechas 13 de junio y 23 de septiembre de 2003, el "Tribunal Nacional de Elecciones" se reorganiza como Tribunal Supremo Electoral y al año siguiente se emite el Decreto n. ${ }^{\circ} 44-2004$ de fecha 15 de mayo de 2004, con el cual entra en vigencia la Ley Electoral y de las Organizaciones Políticas. 
A partir de esta nueva década, varios organismos electorales han iniciado movimientos tendientes a fortalecer sus capacidades instaladas, ampliar sus competencias y evolucionar hacia formas superiores que les permitan ser más eficientes y proactivas en su rol dentro de la democracia. En Honduras, el TSE estaba siendo depositario de responsabilidades para manejar fondos para la capacitación de los partidos políticos, ampliar su comunicación en lenguas propias de comunidades afrodescendientes. En el listado de recomendaciones que contiene el informe de la CVR está la relativa a cambios en la institucionalidad electoral que plantea nuevos mecanismos para la selección de candidatos a magistrados del TSE y asegurar a la institución una mayor independencia de los partidos políticos y reforzar el Registro Nacional de las Personas (RNP) en virtud de que la tarjeta de identidad es el fundamento de la seguridad jurídica personal y el instrumento de identificación para todas las relaciones del ciudadano con el Estado, por lo que los partidos políticos no deberían ser gestores de la tarjeta de identidad. En Guatemala, la demanda por una reestructuración del TSE fue abanderada por el Comité Coordinador de Asociaciones Agrícolas, Comerciales, Industriales y Financieras (CACIF) y la Comisión Específica de Asuntos Electorales del Congreso de la República (CONAREP), coincidiendo con la necesidad de que las funciones jurisdiccionales del TSE no se vean afectadas por sus funciones administrativas y logísticas propias de un proceso electoral. En este sentido, el CACIF propone la creación de dos direcciones internas: la Dirección General del TSE tendría a su cargo la gerencia administrativa de dicho tribunal y constituiría el enlace entre los magistrados y los órganos permanentes de la institución; y la Dirección General del proceso electoral tendría a su cargo la organización y gestión de dicho proceso.

La propuesta de la CONAREP coincide con la separación de funciones, pero difiere en cuanto a que plantea la creación de un órgano nuevo, el Consejo Superior Electoral, que tendría a su cargo la organización y conducción del proceso electoral, dejando al Tribunal la función estrictamente jurisdiccional.

Como ya vimos, en Costa Rica, después de varios años de espera, se aprobaron finalmente las reformas electorales que entre otros cambios asigna al Tribunal Supremo de Elecciones más funciones, pasando de ocho a diecinueve. Al aumentar las atribuciones al TSE, el espíritu del legislador era darle la autoridad necesaria como para cumplir responsabilidades en ámbitos hasta ahora inéditos para la legislación electoral; tales como el ejercicio efectivo de la jurisdicción electoral, la tutela de los derechos políticos fundamentales, la promoción de la ciudadanía activa y la intervención y el control en materias como el financiamiento de las campañas y la democratización interna de los partidos políticos. Las atribuciones asignadas por la nueva legislación se agrupan en cinco categorías específicas: 1. Administración electoral; 2 . Jurisdicción electoral; 3. Funciones cuasi legislativas; 4. Promoción ciudadana; y 5. Funciones de jerarca administrativo. 
Se establece que la integración ordinaria del TSE es de tres magistrados propietarios. Sin embargo, un año antes y seis meses después de las elecciones para elegir presidente $y$ vicepresidentes de la República y diputados a la Asamblea Legislativa, el Tribunal deberá integrarse con sus magistrados propietarios y dos de los suplentes escogidos por la Corte Suprema de Justicia, pasando a un Tribunal de cinco miembros. En cuanto a su estructura, lo más importante es la creación de la Dirección General del Registro Electoral y de Financiamiento de Partidos Políticos (REFPP) y el Instituto de Formación y Estudios en Democracia (IFED). ${ }^{33}$

En la República Dominicana ya vimos cómo se fortaleció la autoridad electoral con la creación del Tribunal Supremo de Elecciones. Este vino a asumir la función jurisdiccional que anteriormente se le encargaba a una Sala de la Junta Central Electoral.

Solo El Salvador se ha quedado corto en reformas para mejorar la calidad de la administración de los procesos electorales y la justicia electoral. De hecho, por primera vez desde su vigencia en 1994, el TSE ha sido señalado de parcial y de una conducta fraudulenta en estas elecciones de 2014. De hecho el partido ARENA denunció a los magistrados del TSE ante la Fiscalía General de la República por ilícitos que afectaban su desempeño.

Desde varios foros y en múltiples ocasiones, desde la postguerra, hemos clamado por la despartidización de la entidad, así como por la separación de ambas funciones en dos entes diferentes. Pero los partidos políticos se sienten cómodos con el diseño actual y ninguno de los que tienen capacidad legislativa como para realizar los cambios se decide a hacerlo.

Veremos qué sucede con la integración del próximo TSE en julio de 2014, pues existe una sentencia de la Sala de lo Constitucional de la Corte Suprema de Justicia, que prohíbe la elección de funcionarios a cargos en los que se debe de respetar el principio constitucional de independencia judicial, para aquellos ciudadanos afiliados a partidos políticos. Desde ese criterio se declaró inconstitucional la elección del presidente de la Corte Suprema de Justicia y de los magistrados de la Corte de Cuentas. Si se aplica a los magistrados del TSE, tendremos entonces a partir del 1 de agosto un TSE despartidizado, sin necesidad de reformar la Constitución. ${ }^{34}$

\section{Régimen financiero más justo $y$ transparente. Blindaje de programas sociales de los Gobiernos}

Una de las grandes fallas que presentan los sistemas electorales de la región es la deficiente regulación de las finanzas en la política. El riesgo permanente de caer en una plutocracia o, peor aún, en un sistema político financiado por dineros oscuros provenientes de actividades ilícitas, ha hecho que en todos los países, sin excepción, se hayan presentado en los

34 Con fecha 13 de Junio de 2014 la Sala de lo Constitucional de la Corte Suprema de Justicia declaró inconstitucional la elección del presidente del Tribunal Supremo Electoral, por su filiación partidaria, aunque declaró válidos los actos realizados y falló que puede terminar su mandato que vence el 31 de julio de 2014. 
últimos años propuestas de reformas en esta materia.

A la fecha, El Salvador que era el único país del istmo sin ningún tipo de regulación para el financiamiento privado, emitió una tímida Ley de Partidos Políticos, donde esboza algunas normas para su regulación a partir de las elecciones de 2018. Costa Rica, por su parte, aprobó, mediante transitorio, una reducción al $0,11 \%$ del PIB el costo de las elecciones con el argumento de que:

Fue evidente en las campañas nacional y municipal del año 2010 que ese monto fue SUFICIENTE para la sana realización de las elecciones; ya que la mayoría de los problemas manifestados por los partidos políticos, se debieron a dificultades por falta de liquidez, de vender y cesión de los bonos de deuda política o por asuntos administrativos y fiscales para la justificación posterior de la misma y no al monto asignado en cuestión. Se demostró además que nuestro sistema democrático no necesita tanto dinero para ser efectivo y que en ocasiones algunos partidos políticos malgastan mucho dinero en eventos, salarios, publicidad en medios de comunicación colectivos, signos externos, transportes entre otros. ${ }^{35}$

Como sabemos, la equidad es una forma correctiva de la justicia (justicia distributiva, según John Rawls) porque al tener la ley carácter general se hace necesario adaptar el mandato normativo a las circunstancias concretas del caso específico. Así, lo justo y lo equitativo son lo mismo, sostiene Aristóteles, quien además afirma: "La naturaleza misma de la equidad es la rectificación de la ley cuando se muestra insuficiente por su carácter universal”. De tal suerte que una primera idea es que las garantías de equidad en la competencia electoral, mediante el control del financiamiento de la política, constituyen un conjunto de esfuerzos orientados a crear condiciones de competitividad con base en la igualdad de oportunidades, con reglas claras y estándares iguales para los contendientes, sin que la posibilidad de un financiamiento público, privado o mixto inequitativo o sin regulaciones permita ventajas de un contendiente sobre otro. En esa línea de pensamiento, la limitación de los aportes privados, la asignación de fondos públicos, según el grado de representatividad de las fuerzas políticas, la prohibición de políticas estatales con fines clientelares, entre otras, deben ser las garantías del blindaje de un sistema electoral democrático y transparente.

En un listado no taxativo de las deficiencias identificadas en esta materia en los países centroamericanos, podríamos enumerar las siguientes:

a. Hay dispersión de los cuerpos normativos y/o ausencia de regulación.

b. Carencia de atribuciones y recursos para los organismos de control.

c. Falta de independencia de varios de los organismos electorales que ejercen el control, dada su naturaleza partidista.

d. La activación de los mecanismos de control se realiza básicamente por medio de la denuncia.

e. El régimen de sanciones, aunque gradualizado, es de carácter correccionalista.

f. No existen estímulos que promuevan el cumplimiento voluntario de las normas.

g. Falta dar mayor responsabilidad a los organismos de control interno 
de los partidos políticos y regular la participación de las ONG especializadas.

Por su parte, el sistema interamericano en la Carta Democrática establece en su Artículo 5:

El fortalecimiento de los partidos y de otras organizaciones políticas es prioritario para la democracia. Se deberá prestar atención especial a la problemática derivada de los altos costos de las campañas electorales $\mathrm{y}$ al establecimiento de un régimen equilibrado y transparente de financiación de sus actividades". Y en la resolución AG/RES. 2195 aprobada en la cuarta sesión plenaria de la OEA, celebrada el 6 de junio de 2006, se consigna: "Resolución 3. Alentar la transparencia en el manejo de los recursos de los partidos políticos, la lucha contra la corrupción y el tráfico de influencias, y la promoción de igualdad de oportunidades entre los militantes de los partidos políticos.

Es decir que no hay ninguna duda del derecho congénito de los partidos al financiamiento en cualquiera o en todas sus formas; pero bajo una normativa regulatoria que garantice la equidad en la contienda electoral para que todos los actores gocen de igualdad de oportunidades al momento de competir.

Finalmente, quiero resaltar que una de las formas más inequitativas que se presenta generalmente en todos los torneos electorales, es el uso de los programas, recursos y bienes del Estado por parte de los candidatos a la reelección o de los partidos gobernantes. Los casos de Nicaragua en 2011 y de El Salvador en 2014 son una evidencia de esta inequidad que sin duda otorga ventajas enormes a los candidatos y partidos gobernantes. En ambos casos el partido oficial y el presidente de la República echaron mano de los programas sociales como temas de campaña, como si estos no se hubieran ejecutado por funcionarios nombrados para ese propósito y además con fondos públicos. Pero también es una mala práctica que se puede corregir, y de hecho hay un buen ejemplo en México que vale la pena relatar.

De cara a las elecciones de julio de 2006, el 23 de noviembre de 2005 se integró en México un organismo llamado Alto Consejo por la Transparencia de los Programas Sociales Federales, con 12 académicos y expertos en temas electorales y de política social. Esta iniciativa del Programa de las Naciones Unidas para el Desarrollo (PNUD) buscaba evitar el uso electoral de los programas sociales. El Alto Consejo presentó 10 recomendaciones para evitar que los programas sociales fueran utilizados con fines proselitistas en el proceso electoral federal 2006 en beneficio de cualquier partido político. También exhortó al Gobierno federal a cumplir con: (i) Las reglas de neutralidad emitidas por el IFE $^{36}$ para que todos los servidores públicos del país, empezando por el presidente de la República, se abstuvieran de realizar campañas publicitarias o promoción de programas de obra pública o de desarrollo social a cambio de la promesa del voto; ii) Leyes, acuerdos y decretos del Gobierno federal que blindan y transparentan los recursos de los programas sociales; (iii) Los procedimientos de procuración de justicia penal electoral de manera expedita,

36 Hoy Instituto Nacional Electoral INE a partir de abril de 2014. 
contribuyendo con esto a una efectiva cultura de la legalidad y de la denuncia. Esta loable experiencia se repitió en las elecciones del 2012, con la buena noticia de que en esta ocasión además del PNUD también participó Transparencia Mexicana. De nuevo SEDESOL estuvo a la altura de las circunstancias y 48 programas federales y 836 estatales fueron blindados. ${ }^{37}$ Más recientemente nos enteramos de que el dictamen del Senado sobre la Ley General de Delitos Electorales ha propuesto hasta seis años de prisión para aquellos funcionarios que condicionen la implementación de programas sociales a la emisión del voto por un determinado partido político.

\section{Calendario electoral y reelección presidencial}

Una de las discusiones más encendidas que han dejado las últimas tres elecciones en Centroamérica es su organización y el calendario electoral. Honduras celebró sus elecciones generales el 24 de noviembre de 2013, para elegir al presidente de la República (más 3 designados), 128 diputados al Congreso de Honduras, 20 diputados al Parlamento Centroamericano, 298 alcaldes y 298 vicealcaldes, así como regidores. En Honduras funciona el sistema de mayoría simple, por eso el presidente fue elegido con el $36,9 \%$ de los votos válidos.

Costa Rica y El Salvador fueron a elecciones el mismo día 2 de febrero de 2014, con la diferencia de que en ningún país hubo ganador en la elección presidencial, porque ambos tienen el sistema de mayoría absoluta; Costa Rica exige el $40 \%$ de los votos válidos y El Salvador, el 50\% más un voto. Ninguno de los contendientes pasó dicho umbral, por lo que en El Salvador se celebró una segunda ronda electoral el 9 de marzo y en Costa Rica el 6 de abril. Con la salvedad de que en Costa Rica ya quedaron elegidos los parlamentarios y los miembros de los gobiernos locales, mientras que en El Salvador, habrá elecciones parlamentarias y municipales en marzo de 2015, con las consiguientes quejas de la ciudadanía, que no solo se ve agotada por convocatorias electorales continuas, sino también por el gasto que implican y que tienen que cubrir con las exiguas arcas del presupuesto nacional.

El tema de la segunda vuelta parece no preocupar a ninguno de los actores principales, excepto al candidato que quedó en segundo lugar en Costa Rica y que a pesar de no estar habilitado por la Constitución, anunció que se retiraría de la contienda. ${ }^{38}$ Lo que está en discusión tanto en El Salvador como en Honduras es la celebración de elecciones generales o elecciones de medio término. Mientras los hondureños están planteando dividir las elecciones y separar las presidenciales de las legislativas y municipales, en El Salvador el clamor es porque se celebren elecciones generales para todos los cargos electivos.

Y cuando creíamos que en la República Dominicana, siguiendo el modelo de los Estados Unidos, las elecciones de medio término generaban el balance entre los Órganos o Poderes del Estado republicano, al celebrar cada cuatro años elecciones presidenciales y en el medio de su término o sea en el año dos del mandato presidencial, las elecciones legislativas, nos sorprende la reforma de que tales elecciones han sido unificadas. ${ }^{39}$ Como hemos dicho en otras

38 En la República Dominicana hay una disposición legal que permite a cualquiera de los dos finalistas desistir de participar en la segunda elección. 
ocasiones, no hay sistemas electorales buenos o malos, mejores o peores entre sí; son las condiciones de cada nación y cada Estado las que generan las reglas de la competencia.

\section{La reforma electoral por la vía de la jurisdicción constitucional}

Finalmente, es importante considerar una variable que ha venido a modificar las reglas electorales e impactar los sistemas políticos sin que nos hubiéramos imaginado tal condición al inicio de este siglo. Se trata de las reformas a los sistemas electorales por la vía de la jurisdicción constitucional.

La inició el expresidente de Costa Rica, Oscar Arias, cuando acudió a la Sala IV de la Corte Suprema de Justicia, solicitando mediante un recurso de amparo, se le habilitara su postulación para un segundo mandato. La Sala, el 4 de abril del año 2003, dio un fallo que revocó una norma jurídica constitucional aprobada en 1969 que prohibía la reelección. Luego, en El Salvador, la Sala de lo Constitucional de la Corte Suprema de Justicia emitió un fallo el 29 de julio de 2010, ante una demanda de inconstitucionalidad modificando el sistema de elección legislativa de listas cerradas y bloqueadas, por un sistema de listas cerradas, pero desbloqueadas y habilitando las candidaturas ciudadanas sin necesidad de ir en las listas de los partidos políticos. Finalmente, en Nicaragua el presidente Ortega utilizó el recurso de amparo para que la Sala Constitucional le permitiera presentarse a las elecciones presidenciales en el periodo inmediato al que estaba ejerciendo. La Sala lo favoreció declarando inconstitucional la norma de la Constitución que prohibía la reelección continua "por violar derechos humanos", dijeron los togados. Como lo relata Angelo Olivieri:
Lo que había hecho el caso nicaragüense grotesco fue que el límite constitucional de los dos mandatos, que volvía automáticamente ilegítima la presidencia de Ortega, fue declarado "inaplicable" por la Corte Suprema de Justicia, mediante la Sentencia No. 504/2009, que definía el mismo límite incompatible con las condiciones de igualdad entre los ciudadanos expresadas en la misma Carta Fundamental: en declarar Ortega no elegible, la Constitución era "inconstitucional". $\mathrm{Y}$, sin embargo, la prohibición de la reelección, o su limitación a dos mandatos, es uno de los pilares de los sistemas presidenciales en todo el continente americano, desde Ushuaia hasta Point Barrow. Incluso en Argentina, Chile, Costa Rica y Uruguay, donde no existe un límite numérico para los mandatos, es necesario saltar un turno, lo que evita la perpetuación en el poder de la misma persona. ${ }^{40}$

Estos tres eventos sumados a otros fallos que ha emitido la Sala de lo Constitucional de la Corte Suprema de Justicia de El Salvador, como el que declaró inconstitucional la elección de dos magistrados del TSE, o cuando sin necesidad de un fallo definitivo, con la simple admisión de demandas ciudadanas contra la Asamblea Legislativa por no legislar en el caso del voto de los salvadoreños desde el exterior o la integración de los Concejos Municipales plurales, al solicitarle informe en plazo perentorio de diez días, la Asamblea Legislativa emitió la legislación en mora, han generado unas corrientes de opinión 
en los foros regionales y en los círculos políticos y legislativos sobre las facultades, alcances y competencias de los tribunales constitucionales sobre el principio de configuración legislativa exclusiva e inherente a los legisladores.

\section{Conclusión}

Acosado y derrotado en varios frentes, Napoleón Bonaparte firmó con Fernando VII el Tratado de Valencay, el 11 de diciembre de 1813. Con base en este instrumento se le restituían al rey todos sus derechos, sus propiedades, territorios y los súbditos que poseía antes de 1808, reconociéndolo como rey de España. Fernando fue liberado y regresó a España el 24 de marzo de 1814, negándose a seguir el camino marcado por la Regencia y entró en Valencia el 16 de abril. Estaba molesto por la disminución de su poder, por lo que abolió con fecha 4 de mayo de 1814 la Constitución que había sido promulgada por las Cortes de Cádiz.

Se persiguió a los liberales con saña, quienes tuvieron que irse al exilio y, durante este retorno a la monarquía absoluta, desaparecieron la prensa libre, las diputaciones y los ayuntamientos constitucionales; se cerraron las universidades, se restablecieron los gremios y se devolvieron las propiedades confiscadas a la Iglesia. Fuerzas expedicionarias se enviaron a América con el propósito de suprimir, por la vía de las armas, los intentos libertarios de las colonias.

En el reino de Guatemala, amparado por el absolutismo de la corona, el capitán general José de Bustamante se sintió con fuerza para acabar definitivamente con las pretensiones autonomistas de los criollos agrupados en el ayuntamiento capitalino salvadoreño.
Han transcurrido doscientos años desde la fecha en que en San Salvador se celebraron elecciones para elegir a los miembros del Ayuntamiento Constitucional el 23 de enero de 1814. Los criollos ganaron ampliamente las elecciones. Sin duda los elegidos no gozaban de la confianza del intendente José María Peinado, quien las anuló dos veces, por lo que se estableció una sorda hostilidad entre éste y el Ayuntamiento. Con instrucciones de Bustamante se capturó a los electos y se iniciaron los famosos Procesos de Infidencia de 1814 a 1818 en contra de nuestros próceres. ${ }^{41}$

Dos siglos más tarde la región presenta una realidad muy diferente, y no podríamos terminar estas notas sin recordar que hace más de una década América Latina decidió romper con una filosofía política y económica que llevaba el sello del Consenso de Washington y comenzó a elegir gobernantes alejados de dicha doctrina. Por haberse realizado mediante las formas democráticas, dentro de la institucionalidad de los Estados y siguiendo los causes electorales, a esta transición se comenzó a llamar la primavera democrática de América Latina.

Los resultados son mesurables y nos los relata el citado informe de Latinobarómetro así:

En esta primera década del siglo, América Latina experimenta por primera vez en su historia un crecimiento económico sostenido por seis años consecutivos con todos los países en democracia. Seis años no es un período largo de tiempo, pero es mucho más de lo que nadie tiene recuerdo. Por primera vez se acumula, se sostiene, se prevé, se 
planifica, se estabiliza el empleo, en otras palabra se ve un horizonte más allá del "mañana".

Pero las buenas noticias en la economía no corresponden a la frustración con la política, con los políticos, con los partidos políticos. Una ciudadanía más educada, mejor alimentada y con expectativas mayores está atenta y participa de los grandes eventos políticos y electorales. $Y$ no está satisfecha. El mismo informe recoge ese sentimiento: "Al no sentirse los ciudadanos representados por el sistema de partidos se produce una dispersión

\section{Notas y referencias}

2 Héctor Pérez Brignoli. Población y Salud en Mesoamérica. Revista electrónica semestral, ISSN-1659-0201 Volumen 7, número 2, archivo 1, Archivo: Sección de documentos históricos. Enero - junio, 2010. Publicado 1 de enero, 2010 http://ccp.ucr.ac.cr/revista/ América Latina en la transición demográfica, 1800-1980.

3 "Nosotros, por tanto, los Representantes de dichas Provincias, en su nombre, con su autoridad y conformes en todo con sus votos, declaramos solemnemente: $1^{\circ}$ Que las expresadas Provincias, representadas en esta Asamblea, son libres e independientes de la antigua España, de Méjico y de cualquiera otra potencia así del antiguo, como del Nuevo Mundo; y que no son ni deben ser el patrimonio de persona ni familia alguna". Declaración de Independencia Absoluta de Centroamérica DECRETO DE LA ASAMBLEA NACIONAL CONSTITUYENTE, DEL $1^{\circ}$ DE JULIO DE 1823.

5 Jordi Palou. El concepto de potencia media. Los casos de España y México. Fundación CIDOB, Revista d'AFERS INTERNACIONALS \# 26.Barcelona España. www.cidob.org

6 Jorge Mario García Laguardia. Centro América en las Cortes de Cádiz. www.juridicas.unam.mx/publica/librev/rev/

8 El Dinero y la Democracia.Pág.71 y ss. Félix Ulloa. Editorial Libros en Red, Buenos Aires, Argentina. 2004 ISBN 987-561-118-2.

9 Ulloa, Ob.Cit.

14 Presentación. Conmemoración del XXV aniversario de la Asociación de Organismos Electorales de Centroamérica y el Caribe, Protocolo en muchos casos mucho más allá de lo razonable, de los grupos que intentan representar, que lejos de ser un síntoma de anarquía, es un síntoma de demanda democrática y de cambios por la vía de las reformas y no de la revolución". ${ }^{42}$

Por tanto, la pelota está en la cancha de los políticos, ellos tienen los medios, los recursos para cambiar de rumbo. Los pueblos tienen la paciencia y la sabiduría para saber cuándo actuar.

Artículo recibido: 17 de septiembre de 2014 Artículo aprobado: 13 de octubre de 2014

de Tikal. Secretaría Ejecutiva Centro de Asesoría y Promoción Electoral. Instituto Interamericano de Derechos Humanos. Tegucigalpa, Honduras.

15 El presidente José Napoleón Duarte, de la Democracia Cristiana, le entregó la presidencia al electo Alfredo Cristiani, de ARENA.

17 MÉNDEZ, JUAN. Partidos y Representatividad. PARTIDOS Y ELECCIONES EN CENTROAMÉRICA. Fundaungo y Fundación Friedrich Ebert. Compilación de Ricardo Córdova Macías y Carlos Guillermo Ramos. San Salvador, El Salvador.

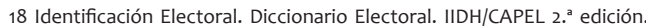
San José, C.R.: IIDH, 2000.

19 Enrique Dussel. Telam América Latina, Reportaje 26.11.2013.

20 Juan José Monsant. Diario El Mundo, San Salvador, miércoles 21 de marzo, 2012.

21 Heinz Dieterich Steffan. Entrevista en Rebelión. 12/10/07.

22 Discurso de despedida al pueblo de los Estados Unidos de George Washington el 17 de Septiembre de 1796. http:// constitucionweb.blogspot.com/2010/04/discurso-dedespedida-de-washington-al.html

23 Discurso pronunciado por Simón Bolívar el 15 de febrero de 1819, en la provincia de Guayana, con motivo de la instalación del segundo Congreso Constituyente de la República de Venezuela en San Tomé de Angostura (hoy Ciudad Bolívar). http://www.venezuelatuya.com/ historia/discurso angostura.htm 
24 THIBAUT, Bernhard. "Instituciones de la Democracia Directa". En Dieter Nohlen, comp. y otros. Tratado de derecho electoral comparado de América Latina. 1. ${ }^{a}$ edición. México: Fondo de Cultura Económica, 1998. Pág. 65. ISBN 968-16-5852-3.

25 ZIMMERMAN, Joseph. Creado: 12/06/99. ACE Project. SISTEMAS ELECTORALES. IFES/UN/IDEA. Traducción al español por José Félix Ulloa. Editorial Guayampopo. San Salvador, Mayo, 2000. ISBN 99923-26-02-6

26 GALLAGHER, Michel. REFERENDUMS Y PLEBISCITOS. En SISTEMAS ELECTORALES. ACE Project. IFES/IDEA/UN. Traducción de José Félix Ulloa. Editorial Guayampopo. San Salvador, Mayo 2000. ISBN $99923-$ 26-02-6.

27 THIBAUT, Bernhard. "Instituciones de la Democracia Directa". En Dieter Nohlen, comp. y otros. Tratado de derecho electoral comparado de América Latina. 1. ${ }^{a}$ edición. México: Fondo de Cultura Económica, 1998. Pág. 65.

28 Félix ULLOA. El Dinero y la Democracia. Un caso de estudio. Pág. 40. Primera Edición. 2004. Libros en Red, Argentina. ISBN 987-561-118-2.

29 Corporación Latinobarómetro. 28 de octubre 2011/ Santiago de Chile. Banco de datos en línea. www.latinobarometro.org

30 Construyendo la Seguridad Ciudadana en las Américas. Paper de Peter Hakim y Kim Covington. Inter American Dialogue. Washington DC, Septiembre 23, 2011

31 Daniel Zovatto. América Central: crece pesimismo por crisis económica e inseguridad. Revista Estrategia y Negocios, 20/11/17.

33 Panorama centroamericano. Reporte Político Año XLII. Época N. ${ }^{\circ}$, Enero-Abril 2012. ISBN 1017-8902.

35 MODIFICACIÓN DEL CÓDIGO ELECTORAL, LEY N.8765, PARA AGREGARLE UN TRANSITORIO QUE MODIFIQUE EL MONTO DEL APORTE ESTATAL PARA LAS ELECCIONES NACIONALES DEL 2014 Y MUNICIPALES DEL 2016. DICTAMEN AFIRMATIVO UNÁNIME. COMISIÓN ESPECIAL DE REFORMAS ELECTORALES Y PARTIDOS POLÍTICOS, EXPEDIENTE N. ${ }^{\circ}$ 17.769, Asamblea Legislativa de Costa Rica. San José, 18 de Septiembre 2012.

37 Informe de resultados IPRO 2012. Transparencia Mexicana y Programa de las Naciones Unidas para el Desarrollo (PNUD), México.

39 Por medio de la disposición transitoria decimosegunda de la reforma a la Constitución del 2010.

40 América en el Mundo, "Nicaragua, la reforma constitucional que favorece a Ortega”, 19 diciembre 2013.

41 Barraza Ibarra, Jorge. Historia del Pensamiento Político en El Salvador. 1800 a la fecha. Primera Edición 2011, San Salvador. Universidad Francisco Gavidia , ISBN 978-99923-47-27-0.

42 Corporación Latinobarómetro. 28 de Octubre 2011/ Santiago de Chile. Banco de datos en línea. www.latinobarometro.org.

\section{Bibliografía}

Barraza Ibarra, Jorge. Historia del Pensamiento Político en El Salvador. 1800 a la fecha. San Salvador: Universidad Francisco Gavidia. 2011.

Corporación Latinobarómetro. 28 de Octubre 2011/ Santiago de Chile. Banco de datos en línea. www.latinobarometro.org

Costa Rica. Código Electoral, Ley N. ${ }^{\circ} 8765$, expediente N. ${ }^{\circ} 17.769$, Asamblea Legislativa de Costa Rica. San José, 18 de Septiembre 2012.

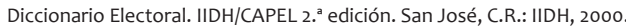

Dussel, Enrique. "En Latinoamérica hay una cierta primavera política que nunca había acontecido”, analiza Enrique Dussel”. En: Telam América Latina, Reportaje 26.11.2013. Tomado de http://www.telam. com.ar/tags/6303-enrique-dussel/noticias

García Laguardia, Jorge Mario. Centro América en las Cortes de Cádiz. Tomado de: www.juridicas.unam.mx /publica/librev/rev/

Hakim, Peter y Covington, Kim. Construyendo la Seguridad Ciudadana en las Américas. Paper de Inter American Dialogue. Washington DC, Septiembre 23, 2011

Heinz Dieterich, Steffan. Entrevista. En: Rebelión. Realizada el 12 de octubre de 2007. http://www.rebelion.org/noticia.php?id=57133

Méndez, Juan. “Partidos y Representatividad”. En: Partidos y elecciones en Centroamérica. Compilación de Ricardo Córdova Macías y Carlos Guillermo Ramos. San Salvador, El Salvador: Fundaungo y Fundación Friedrich Ebert, 1998.

Monsant Aristimuño, Juan José. "Primavera latinoamericana". En: Diario El Mundo, San Salvador, miércoles 21 de marzo, 2012. http:// elmundo.com.sv /category/editorial-opinion/opinion/page/177

Palou, Jordi. "El concepto de potencia media. Los casos de España México". En: Revista Afers Internacionals, (26):7-35, www.cidob. org/es/content/ download/7165/71709/.../26palou.pd

Panorama centroamericano. Reporte Político Año XLII. Época N. ${ }^{\circ}$, Enero-Abril 2012

Pérez Brignol. Héctor. "América Latina en la transición demográfica, 1800-1980". En: Población y Salud en Mesoamérica Revista 7(2):232, enero, 2010 http://ccp.ucr.ac.cr/revista/.

Thibaut, Bernhard. "Instituciones de la Democracia Directa". En: Dieter Nohlen, comp. y otros. Tratado de derecho electoral comparado de América Latina. 1. ${ }^{a}$ edición. México: Fondo de Cultura Económica, 1998

Ulloa, Félix. El dinero y la Democracia. Argentina: Editorial Libros en Red, 2004

Zovatto, Daniel. “América Central: crece pesimismo por crisis económica e inseguridad”. En: Revista Estrategia y Negocios, 2011/11/17. http:// www.estrategiaynegocios.net/ 
